UCID- $\quad 16986-90-1 / 2$

UCID--16986-90-1/2

DE91 000497

\title{
OIL SHALE QUARTERLY REPORT
}

\section{JANUARY - JUNE 1990}

\author{
R. Cena
}

September 5, 1990

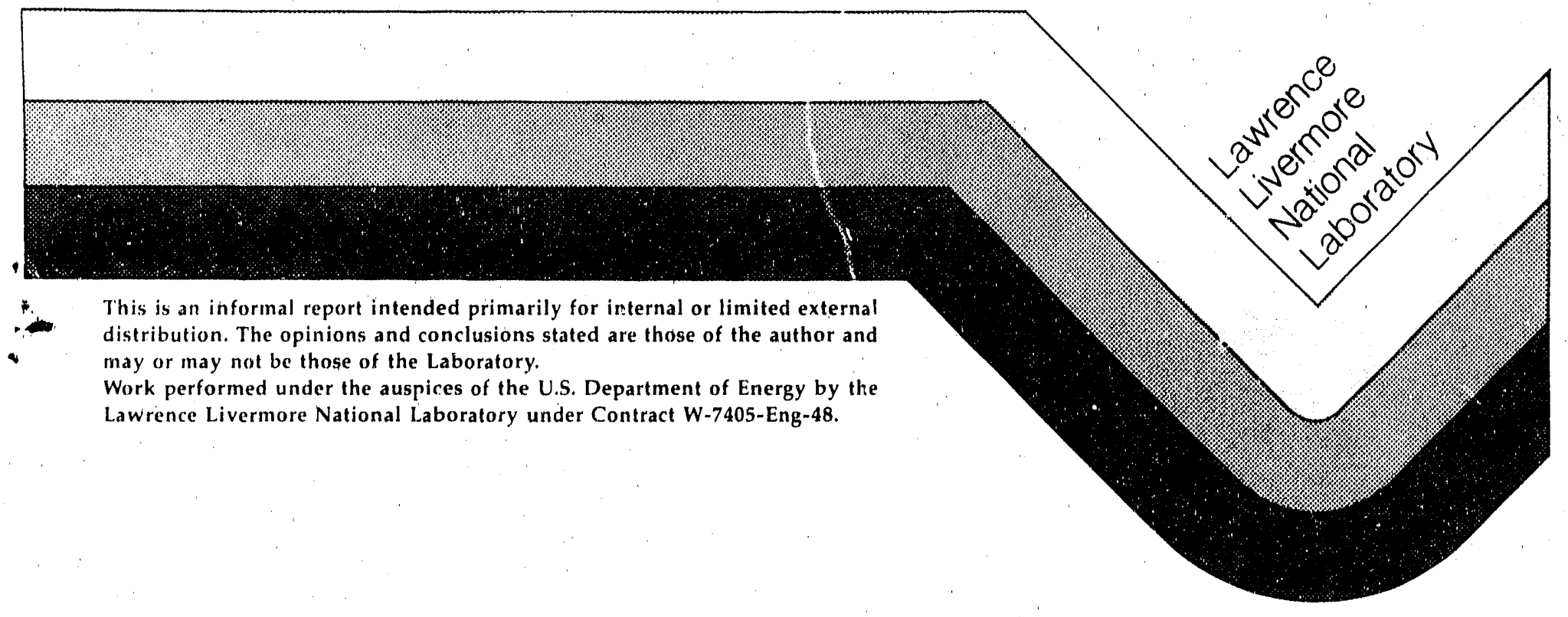


This document was prepared as an account of work sponsored by an agency of the United States Government. Neither the United States Government nor the University of California nor any of their employees, makes any warranty, express or implied, or assumes any legal liability or responsibility for the accuracy, completeness, or usefulness of any information, apparatus, product, or process disclosed, or represents that its use would not infringe privalely owned rights. Reference herein to any specific commercial products, process, or service by trade nanic, trademark, manufacturer, or otherwise, does not necessarily constitute or imply its endorsement, recommendation, or favoring by the United States Covernment or the University of California. The views and opinions of authors expressed herein do not necessarily state or reflect those of the United States Covernment or the University of California, and shall not be used for advertising or product endorsement purposes.

\author{
This report has been teproduced \\ directly from the best available copy \\ Avallable to Dot: and boll: contractors from the \\ Office of Scientific and Technteal intormation \\ li.). Ho: 62, Oak Ridge, TN 378.31 \\ Prices available from (615) $576+8401$, H.TS $626-6401$ \\ Avalable to the public from the \\ National Technical Information Service \\ U.S. Department of Commerce \\ 5285 Porl Royal Rd, \\ Springficld, VA 22161
}

Price

Page

Code

Range

A01

Microfiche

\title{
Papercopy Prices
}

A02

$\mathrm{A} 03$

A04

A05

A06

A07

A08

A09

A10

A11

A12

A13

A 14

A15

A16

A 17

A18

A19

A 20

A 21

A 22

A 23

A24

A 25

A 99
$1-10$

11- 50

$51-75$

76-100

101-125

126-150

151-175

176-200

201-225

226-250

251-275

276-300

301-325

326-350

351-375

376-400

401-425

426-450

451-475

476-500

501-525

526-550

551-575

576-600

601 \& UP 


\section{CONTENTS}

List of Tables iii-iv

List of Figures iv

1. Laboratory Pilot Plant Development

1.1 Introduction

1.2 Description 1

1.3 Pyrolysis Components 3

Fluid-Bed Mixer 3

Packed-Bed Pyrolyzer $3-4$

1.4 Combustion Components $\ldots$

Air Lift Pipe

Delayed Fall Combustor.

Fluid-Bed Classifier

1.5 Results of Cold Flow Tests

$1.6 \cdot$ References

2. Process Modeling

2.1 Model Physics and Chemistry

2.2 Particle Grouping

2.3 Preliminary 4 Tonne-Per-Day Calculations

2.4 References 15

3. Shale Oil Coking Kinetics Over Oxidized Recycle Shale 26

3.1 Introduction $\ldots$

3.2 Model 26

3.3 Experiments 29

3.4 Conclusions - 34

3.5 References 35

\section{LIST OF TABLES}

Table 1.1 Scale of Operations in the Oil Shale Project

Table 2.1. Base Case Raw Shale Particle Size Distribution 17

Table 2.2a. Lift Pipe Solids 18

Table 2.2b. Lift Pipe Gases __..._. 19

Table 2.3a. Delayed Fall Classifier Solids _ _ _... 19

Table 2.3b. Delayed Fall Combustor Gases 19

Table 2.4a. Fluid-Bed Classifier Solids 20

Table 2.4b. Fluid-Bed Classifier Gases $\quad 20$

Table 2.5a. Delayed Fall Mixer Solids _ _ _ _ _ 21

Table 2.5b. Fluid-Bed Mixer Gases 21 
Table 2.6a. Pyrolyzer Solids

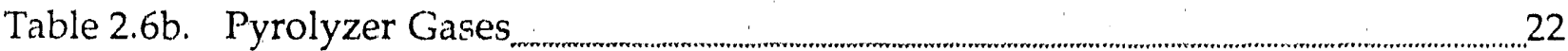

Table 2.7. Oil Production (theoretical $0.233 \mathrm{~kg} / \mathrm{min}$ ) 23

Table 2.8. Rejected (unburned) Carbon as Percentage of Carbon Produced from Pyrolysis and Pyrolyzer Outlet Temperature _.................................. 24

Table 2.9. Overall Dolomite Decomposition _ 24

Table 3.1 Model Parameters used for Comparisons with Experiments $\quad 29$

Table 3.2 Coking Selectivity in Model Calculations for Oil Pulses 32

\section{LIST OF FIGURES}

Figure 1.1 Schematic of Hot-Recycled Solid (HRS) process. 1) Delayed-fall combustor, 2) Fluid-bed classifier, 3) Fluid-bed mixer, 4) Packed-bed pyrolyzer and 5) Air pneumatic lift pipe.

Figure 1.2 Schematic of 4-tonne-per-day pilot plant showing solid-recirculation loop, sensors and controllers 6

Figure 1:3 Pyrolyzer L-Valve Test 7

Figure 1.4 Combustor L-Valve Test _............. 8

Figure 1.5 Lift-Pipe Differential Pressure during L-Valve Operation at a Solid Flow Rate of $10 \mathrm{~kg} / \mathrm{min}_{\text {mannm }} 8$

Figure 1.6 Lift-pipe differential pressure versus solid recirculation rate $\ldots . . . . . . . . . . .99$

Figure 2.1 Computed Average Solid Temperatures at the exit of the Fluid-Bed mixer, Pyrolyzer, Lift, Delayed-Fall Combustor (DFC) and Fluid-Bed Combustor (FBC) 23

Figure 3.1 Model Liquid Gas Phase Equilibrium for Oil Components at $500^{\circ} \mathrm{C} \ldots$

Figure 3.2 Multiple Oil Pulses through Fixed Bed of Oxidized Shale--Experiment 30

Figure 3.3 Multiple Oil Pulses through Fixed Bed of Oxidized Shale--Model ............... 31

Figure 3.4 Multiple Oil Pulses through Fixed Bed of Oxidized Shale-Comparison of Model Results with Experiments 32

Figure 3.5 Coking of Oil Vapor in Packed Bed of Oxidized Shale at $500^{\circ} \mathrm{C}$ Comparison between Model and Experiment. 33

Figure 3.6 Coking of Oil Vapor in Packed Bed of Oxidized Shale at $600^{\circ} \mathrm{C}$ Comparison between Model and Experiment... 


\section{Laboratory Pilot Plant Development}

\subsection{Introduction}

We are studying aboveground oil shale retorting and have developed the LLNL Hot-Recycled-Solid (HRS) process as a generic, second-generation, rapid pyrolysis retorting system in which recycled shale is the solid heat carrier. In 1984-87, we operated a 1-tonne-per-day HRS pilot plant to study retorting chemistry in an actual recirculation loop, Cena (1986). In 1989 we upgraded our laboratory pilot plant to process 4-tonne-per. day of commercially sized shale, which will allow us, for the first time, to study pyrolysis and combustion chemistry using the full particle size, to produce enough oil for detailed characterization studies, to study environmental consequences, and to begin answering the many bulk solid handling questions concerning scale-up of the HRS process.

Unlike many processes in chemical and petroleum industries, oil shale processing requires handling large volumes of solid. Understanding the unit operations of these'solid-handling components and their interaction is a major focus of our current research. Our program plan encompasses the three scales of operation listed in Table 1.1

Table 1.1 Scale of Operations in the Oil Shale Project

\begin{tabular}{lrrc}
\hline Scale & $\begin{array}{c}\text { Tonnes } \\
\text { per day }\end{array}$ & $\begin{array}{c}\text { Pyrolyzer } \\
\text { Diameter }\end{array}$ & $\begin{array}{c}\text { Scale-up } \\
\text { Factor }\end{array}$ \\
\hline & & & \\
Laboratory Test Unit & 4 & $8 \mathrm{in.}$ & $\mathrm{N} / \mathrm{A}$ \\
Field Test Unit & 100 & $1.5 \mathrm{ft}$. & 2.2 \\
Large Pilot Plant & 1,000 & $4.5 \mathrm{ft}$. & 3.0 \\
\hline
\end{tabular}

\subsection{Laboratory Pilot Plant Description}

Our 4-tonne-per-day laboratory facility is designed to test key components of the HRS process, using commercially sized shale, prior to finalizing design of a larger field test. Figure 1.1 shows the major components of the LLNL HRS retorting facility. Itentified in the figure are five key components: 1) A high throughput, short residence time, fluid-bed mixer, 2) a moving-packed-bed pyrolyzer with crossflow gas sweep, 3) a transport air-lift-pipe combustor,4) a delayed-fall combustor, with a five second solid residence time, and 5) a fluidized-bed classifier to control solid discharge and provide a pressure differential to balance the loop. 
3 minutes is provided in our design at a recycled to raw shale ratio of three to one.

Shorter residence times are achieved by simply maintaining a lower bed level. Features include: 1) uniform residence time of solid, 2) short path length for oil vapor collection, with direct applicability to larger scale, since vapor residence time is independent of diameter, 3) smaller reactor volume (less voidage) and less gas sweep than fluid-beds, and 4) process flexibility (e.g. can reduce residence time by lowering bed height).

\subsection{Combustion Components}

Combustion kinetics in solid-recycle systems are poorly understood due to the complexity of the process. Char combustion is sensitive to processing conditions, residual carbon and hydrogen content and sulfur combustion stoichiometry and kinetics. Also nitrogen compound formation and destruction (i.e. $\mathrm{NO}_{x}$ and $\mathrm{N}_{2} \mathrm{O}$ ) in the presence of oxidized shale is poorly understood. In addition, during pneumatic transport, particle attrition solid slip velocities and other particle dynamics for mixed particle systems are not well understood. In addition, dilute phase combustion at low temperature $\left(500-600^{\circ} \mathrm{C}\right)$ is unique to shale processing and has not been fully tested. The low temperatures may result in significant $\mathrm{CO}$ and unburned hydrocarbon emissions while possibly limiting nitrogen oxide and $\mathrm{SO}_{2}$ emissions. On-line sampling during pilot plant runs will allow us to answer these questions concerning gaseous emissions and allow us to test abatement strategies where necessary.

\section{Air-Lift-Pipe Combustor}

We plan to study combustion during pneumatic transport using a $5.4-\mathrm{cm}$ diameter lift pipe system. The lift is designed with $100 \%$ of the air needed to combust the shale. We estimate this represents at least a 30\% air excess since complete combustion will not be possible in the residence time provided. We plan to first study combustion in a $10-\mathrm{m}$ high lift followed by experiments at commercial height $(30-\mathrm{m})$ if reasonable extrapolation of the data is not possible. Complete combustion of the largest particles will not occur in one pass through our combustion system. However, in our design fines are preferentially discharged and the largest particles are recycled, providing multiple passes through the system to complete combustion.

\section{Delayed-Fall Combustor}

Following the lift, the solids enter a classifier and tumble through a series of rods which impede their fall while air is blown either co- or counter-current to the solid. The delayed-fall combustor was designed with a 5 second solid residence time and enough air to bring the solid to the desired recycle temperature. Based on mathematical modeling, co-current air injection appears more efficient, due to a longer retention time for fine shale. We will critically evaluate our modeling results through pilot plant operating experience. 


\section{Fluid-Bed Classifier}

After the delayed-fall combustor, the solid falls into a vessel where the level is maintained to provide a pressure block between the combustion and pyrolysis atmospheres. functions:

In our HRS retorting system the fluid-bed classifier will perform three main

1) Provide a solids discharge from the circulating loop in such a way that the rejected material includes the smallest circulating particles

2) Provide a surge tank to smooth irregularities in solids loop flow

3) Provide an increase in gas pressure to balance the pressure decrease which occurs in the lift pipe

In addition, if the fluidizing gas contains oxygen, combustion of residual char will occur in the classifier. We designed the classifier with a 1 to 2-minute shale residence $i$ ie to control solid recirculation and accommodate surges. At commercial-scale, based on a reasonable bed cross-section and maximum 2 minute shale residence time (to avoid excessive carbonate decomposition), a maximum of ten to fifteen percent of the total fuel combustion could occur in this unit. Less combustion could be obtained via flue gas recycle to the fluid-bed.

\subsection{Results of Cold-Flow Tests}

We've operated our 4 tonne-per-day pilot plant, circulating solids at ambient temperature. During these tests we've monitored solid inventory, gas and solid flow rates and pressures throughout the recirculating system. A simplified schematic of the pilot plant showing the solid-recirculation loop, sensors and controllers is shown in Figure 1.2. 


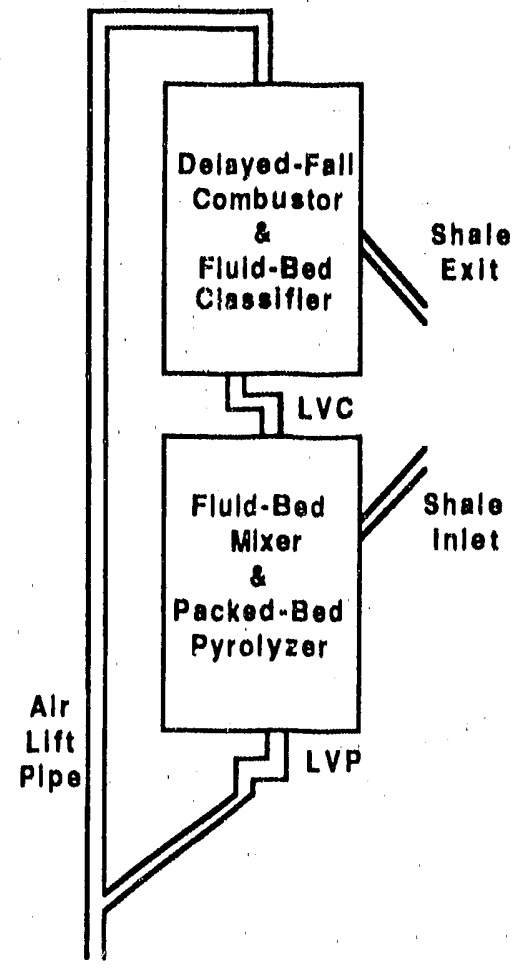

(A) Schematle of solld recicurlation loop

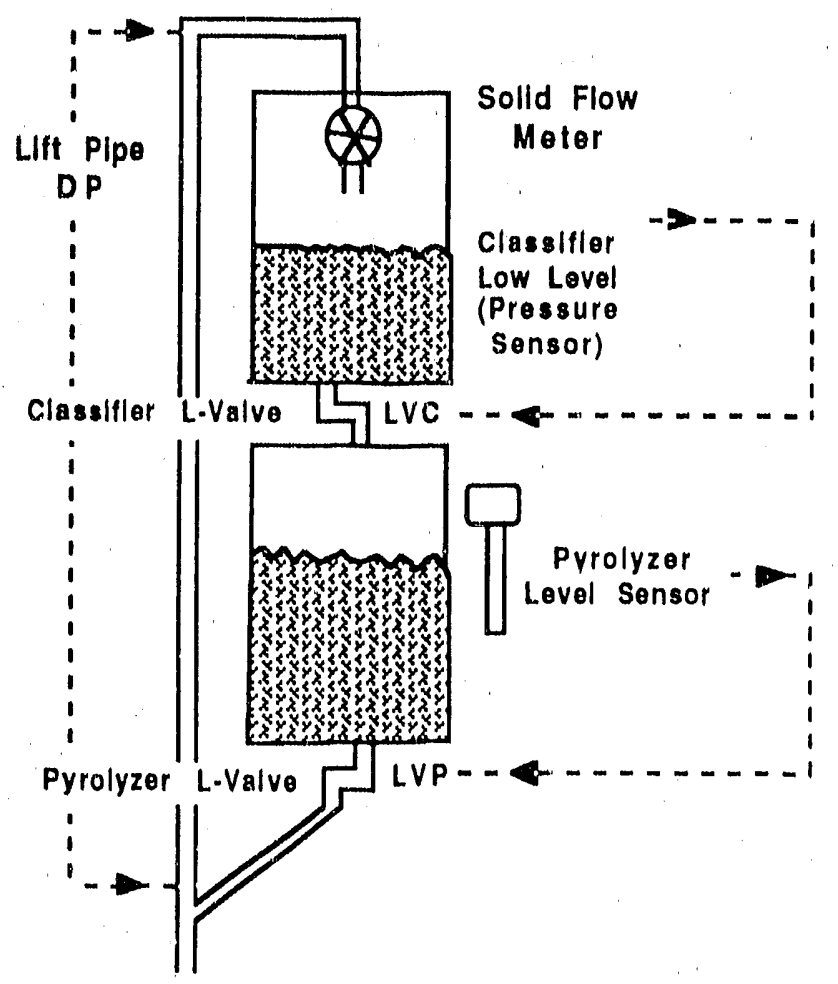

(B) Solld sansors and controllers

Figure 1.2 Schematic of 4-tonne-per-day pilot plant showing solid-recirculation loop, sensors and controllers.

Two L-valves are used for solids flow control, one below the pyrolyzer and the second below the fluid-bed classifier. Each valve contains a skid with continuous and pulsed (via a solenoid valve) gas supply. The continuous gas keeps the jets located along the skid clear. When the solenoid opens, the combined gas pulse forces a quantity of solids through the valve. Approximately $250-300$ gms of solids are moved for each $100 \mathrm{~ms}$ gas pulse. The design solid flow rate is $10 \mathrm{~kg} / \mathrm{min}(7.5 \mathrm{~kg} / \mathrm{min}$ recycled shale and $2.5 \mathrm{~kg} / \mathrm{min}$ of raw shale). This solid rate is achieved using approximately $30-40$ pulses of the L-valve per minute. The pyrolyzer L-valve (LVP) is controlled using a sensor (a gamma source and detector) which continuously monitors the solid level in the moving-packed-bed pyrolyzer. Using a computer algorithm, the LVP pulse rate is adjusted to maintain a constant solid level in the pyrolyzer.

The second L-valve (LVC), below the combustor, determines the burned shale solid recirculation rate. The design recirculation rate is $7.5 \mathrm{~kg} / \mathrm{min}$. For this valve, the computer algorithm monitors but does not control the solid flow except to suspend operations when a low fluid-bed level is indicated. Operationally, LVC and the raw feeder are started and the computer algorithm adjusts LVP to maintain a constant pyrolyzer level. Once stable operation is achieved, we use a rotary valve, installed above the combustor, to periodically measure the solid recirculation rate. We have found that this rate correlates with the lift-pipe differential pressure (DP), integrated over a number 
of pulses. Our plan is use the lift pipe DP for routine indication of solid recirculation rate, with the rotary valve used only periodically for verification.

Figures 3 and 4 show the operation of the L-valves under ambient conditions with no pressure differential across the valves. During operation, as each pulse entering the lift-pipe causes a pressure surge, proportional to the solids loading. Figure 5 shows a typical pressure response. By integrating the pressure signal over a number of pulses, we obtain a rough measure of solid recirculation rate, which we are attempting to correlate with the rate measured via the rotary valve above the classifier.

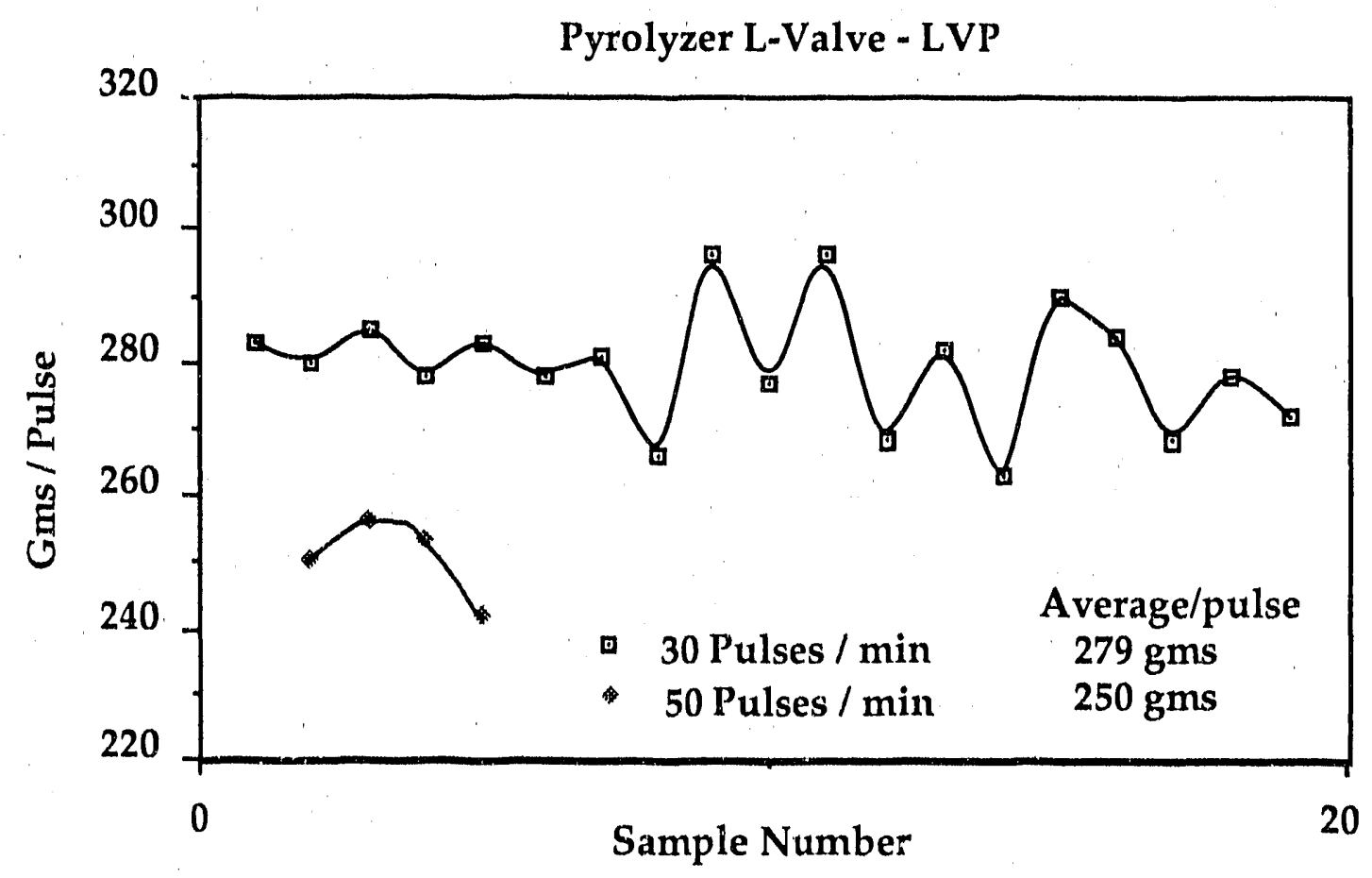

Figure 1.3 Pyrolyzer L-Valve Test Results 
8

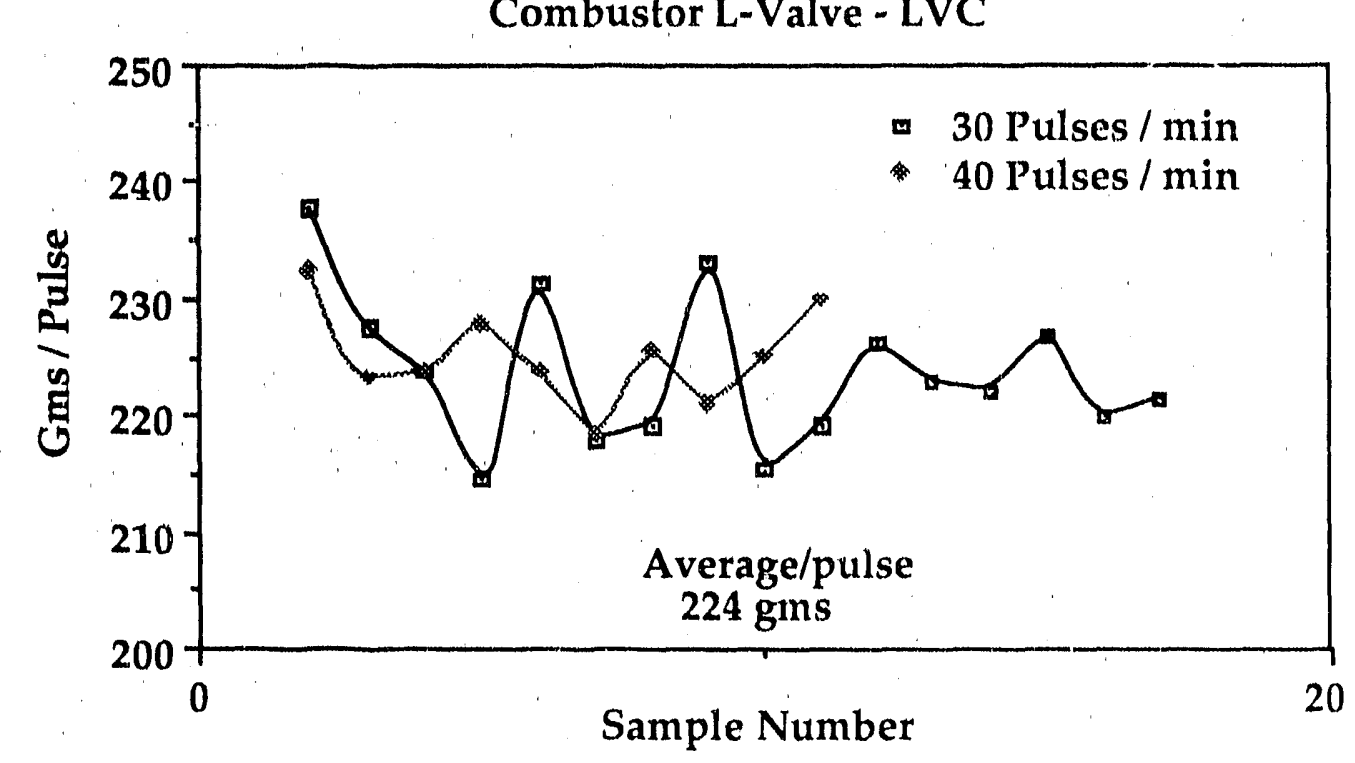

Figure 1.4 Combustor L-Valve Test Results

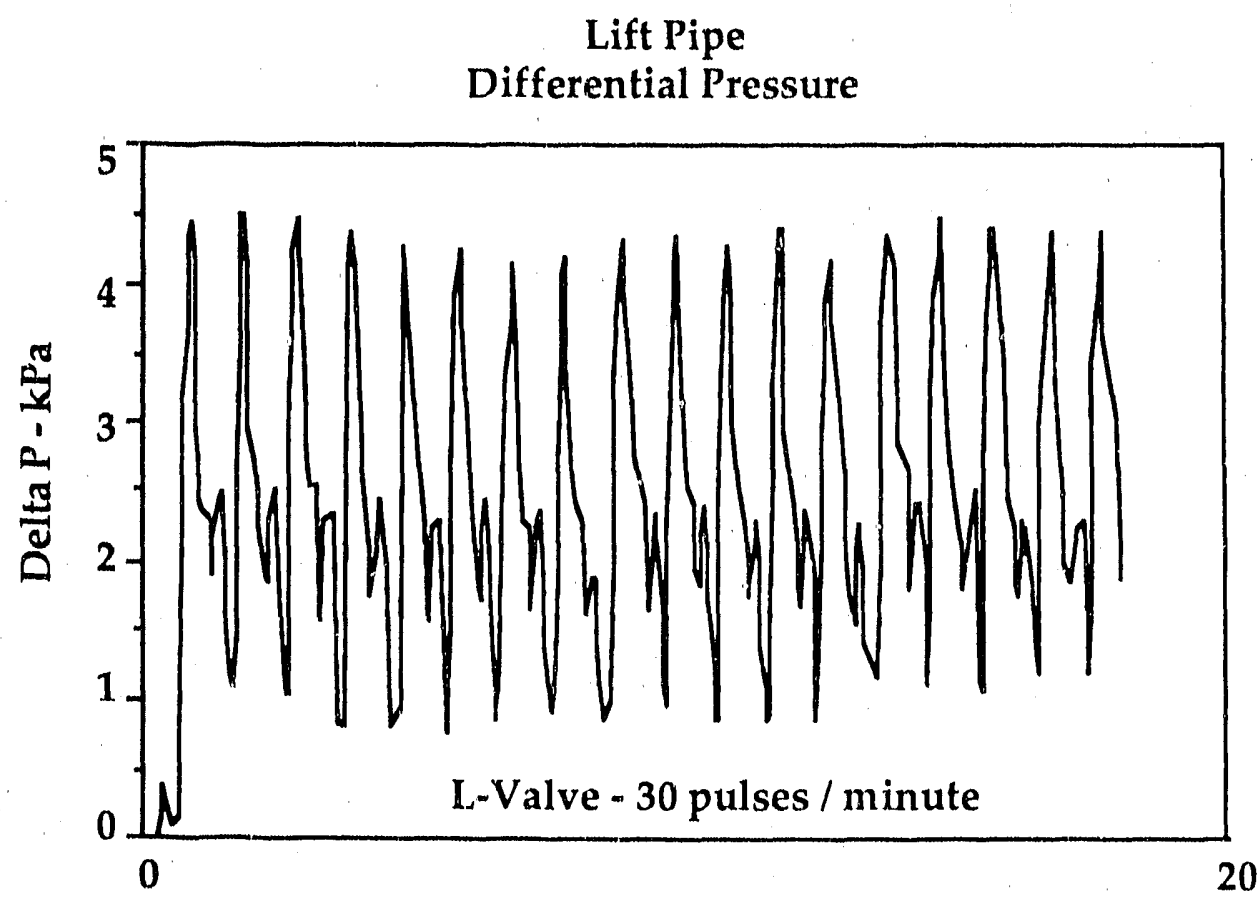

Figure 1.5 Lift-Pipe Differential Pressure during L-Valve Operation at a Solid Flow Rate of $10 \mathrm{~kg} / \mathrm{min}$. 
Figure 1.6 shows our ambient temperature results to date correlating lift-pipe pressure drop versus solid flow rate. The results do show some scatter which cannot be fully accounted for by operating condition changers. However, these results were collected during shakedown of the apparatus, which may account for some of the scatter. We will continue our measurements to the degree of accuracy offered by this solid flow measuring method.

We have completed our ambient temperature testing and are beginning operations at elevated temperature (using dolomite rather than shale) to test calrod and gas heaters and further test solid recirculation dynamics. Once we achieve stable operation under these conditions, we will be ready to operate the complete HRS pilot plant using Anvil Points 24-gpt shale and produce oil.

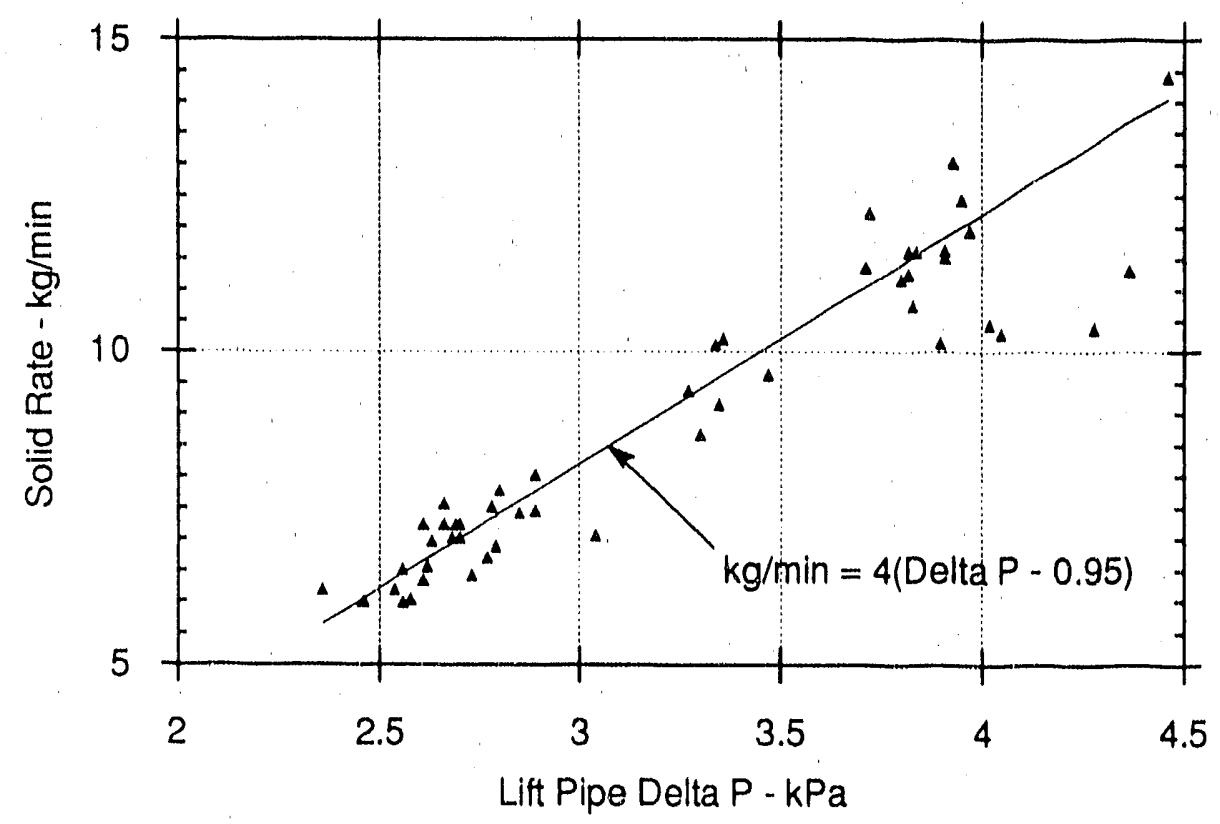

Figure 1.6 - Lift-pipe differential pressure versus solid recirculation rate 


\subsection{References}

1-1. Cena,R.J., and R.G. Mallon. 1986. Results and Interpretation of Rapid-Pyrolysis Experiments Using The LLNL Solid-Recycle Oil Shale Retort. 19th Oil Shale Symposium Proceedings, ed. J.H. Gary, p. 102-125. Golden, Colorado: Colorado School of Mines Press.

1-2. Coburn, T.T., R.W. Taylor, CV.J. Morris and V Duval. 1988. Isothermal Pyrolysis and Char Combustion of Oil Shales. International Conference On Oil Shale and Shale Oil in Conjunction with 21st Oil Shale Symposium, ed. Prof. Zhu Yajie, p. 245-252. Chemical Industry Press, Beiging China. 


\section{Process Modeling}

The development of process models for surface retorting of oil shale serves several purposes. In developing a model one is forced to come to grips with many of the details of the process which might escape a less structured analysis. In this way the development of a model serves as an aid to critical thinking about the important aspects of the process. A process model is also useful in helping to make decisions between various process options and in facilitating estimates on process scale-up. As a result, as part of our mission to develop a technical base to assist in the advancement of oil shale retorting technology we are continuing to develop our modeling capability.

Our current efforts in process model development are focused on a model which allows any number of process units, associated with shale retorting, to be connected together to allo' $N$ an overall simulation of a given process geometry. This Oil Shale Process (OSP) model will compliment our earlier model development work which concentrated on transient behavior of individual processes. OSP is a steady-state model which is being implemented on a UNIX based work station primarily in FORTRAN. Although it allows any number of process models to be coupled together it has the flexibility to control the operation of a single moulule as a stand alone unit.

The general layout of the model consists of three interacting parts: a control portion which handles overall direction of computation and is responsible for coupling process units together through the use of stream variables; a service routine portion which allows common properties to be computed; and any number of process modules which do the actual computations associated with a given unit operation. The model configuration to be executed is driven by an ASCII input file which also contains information on specified input streams. The model defines three type of streams: solid, gas and liquid. The model treats the solid streams as a homogeneous collection of particles of a specified size. Multiple particle size systems are considered by specifying multiple solid streams. The number of the streams is limited only by computationai constraints. The current version has been run with as many as 34 modules and 100 process stream:s, with 14 streams entering a single module. Each stream has an associated flow rate, composition, and other defining parameters. Currently 23 solid species, 24 gas species and 5 oil species can be tracked. The model selects among these 52 components when generating a particular sub-model. This allows substantially enhanced computational performance when simpler systems are being considered.

The first generation of the OSP consists of a preliminary set of 10 process modules which can be selected to generate the desired overall process. These Version 1.0 models have been kept relatively simple but allow many of the desired physical and chemical process to be modeled. Although not completed the basic components of each process unit are in place and can perform useful calculations. The currently defined modules are the following: 
- ATTRITION - This module allows two simple particle attrition models to be used. In one mode it is assumed that a given particle breaks into $n$ different particles. The number of different particle sizes, the size of the new particles and the amount of each size are inputs to the module. All the produced particles are assumed to have the same composition as the parent particle. A second mode allows the model to compute the breaking off of part of the burned-out shale layer from a core of spent shale. In this mode it is assumed that some fraction of the outer layer of kerogen and coke free material flakes off the particle. The fraction of the burned-out layer which flakes off and the size of the generated completely burned-out particles are inputs to the module. In this case the produced solid particles have not only a different dimension than the parent particle but also may have a different average composition.

- BALANCE - This module allows a complete material and energy balance to be performed around any desired control volume. Input to the module is simply the stream designations for all streams crossing the control volume boundaries. This module is called by all other modules automatically to allow a check of their final results to be available for exarnination.

- CO CURRENT - This module assumes that the process to be modeled is basically one dimensional and that gas and solids are flowing in the same direction. Provisions are made for computing changes in temperatures of each particle size group as as well as the gas phase temperature as a result of combustion, pyrolysis, and mineral decomposition. Transport of material and energy between solid and gas phases is computed as well as changes in composition. The relative velocity of gas and solids is determined by the input of the unit's length and diameter as well as the velocity of each solid particle size group. This formulation is most useful in computing results in diluia phase systems where the solid velocity through the unit is controlled by mechanisms other than simple interaction between gas and solid phases. An example of such a unit would be a delayed fall combustor where solid shale particles fall downward through a series of rods.

- CNTR CURRENT - This module assumes that the process to be modeled is basically one in which solids and gases move in a counter-current fashion relative to each other. The same basic processes are computed as in the co-current module described above. The treatment in this module are more approximate in that no spatial resolution is assumed in the computations. That is the computations assume that for purposes of transport between gas and solid phases the phases are well mixed. To better resolve true counter current behavior multiple modules can be used. Residence times in the module are computed from input of the units' heights and diameters, and estimated particle velocities.

- FLUID BED - This module is a very simple fluid-bed model. Again, the same basic processes are computed as in the CO CURRENT module described above. It is assumed that the solid and gas phases are well mixed. Residence times in the unit are estimated from input values for the unit's height and diameter, and the average void fraction in the bed. Even though this is nominally a fluid-bed module, it can be used to estimate the performance of packed bed systems where 
the gas flow direction is not one dimensional and thus too complicated for the PACKED BED module described below. This is possible because of the current use (to be modified in future versions) of the simple basic assumption underlying the computations, that the gas and solid systems are well mixed. Transport coefficients are computed based on relative gas solid velocities which are in turn based simply on estimated gas velocities tacitly assuming the solid velocities are small relative to that of the gas.

- LIFT PIPE - This module is a very similar to the CO CURRENT module except that the motion of the solid particles is computed based on input values for the gas/solid slip velocity. Each particle size group can be given its own value for the slip velocity

- MERGE STRMS - This module allows multiple streams of solids, liquids and/or gases to be combined. The resulting streams emerging from the module are in thermal equilibrium with each other (i.e. all at the same temperature). The module allows any number of input gas streams which are combined to form a single output gas stream. Similarly multiple input liquid streams are merged into a single output liquid stream. For solid streams a provision is made whereby groups of input solid streams can be grouped to produce an average output solid stream, consequently multiple output solid streams are allowed. In addition to performing required stream mixing functions in the modeled system, this module can be used to compute average properties of groups of streams for use in analyzing the results of a run. This is particularly useful when multiple solid streams enter or emerge from a process unit.

- PACKED BED - This module is a simple packed bed model assuming flow of gas and solids in one direction. The same basic processes are computed as in the cocurrent module described above. Residence time in the bed is defined by solid and gas flow rates, bed diameter and height, and average bed porosity.

- $\underline{R E L A X}$ - This module is strictly a computational aid. It does not represent any real process occurring in the modeled system. Its function is to allow oscillations in changes of solid properties to be dampened during the iteration process required to obtain solutions to systems with solid recycle loops.

- SPLIT STRMS - This module's primary function is to allow a given stream to be split in a specified way generating two new streams. The module can operate on solid, liquid or gas streams in one of three modes. In the first mode a split factor is defined which is the fraction of original stream to go to the first output stream one minus his fraction then becomes the flow of the second output stream. The second mode is similar to the first but in this case the a factor is specified which is greater than one. This effectively multiples the stream flow rate. In this mode there is only one output stream for each input stream. This function is useful when one is modeling identical units operating in parallel. The final mode allows the module to control the absolute flow rate of an output stream. A. flow 
rate value is specified for the first output stream, the second output stream then contains the leftover flow.

Those modules which do the nontrivial unit computations are based on two underlying core models. These core models rely on one of two simplifying assumptions, one-dimensional co-current flow or complete mixing. The modules relying on the one-dimensional co-current flow model are the PACKED BED LIFT PIPE and CO CURRENT modules. Those relying on the well mixed model are the CNTR CURRENT and FLUID BED modules. In both cases multiple computational units can be used to more accurately represent a single real system component.

In the following the physics and chemistry currently employed in the core models is outlined. This is followed by a description of some computations done to determine how many discretized groups of solid particles are needed to adequately represent a continuous distribution of particle sizes. Finally, some initial computations for our 4 tonne-per-day pilot retort are presented.

\subsection{Model Physics and Chemistry}

Both the one-dimensional co-current flow model and the well mixed model use the same basic underlying physical and chemical descriptions of the system. These formulations have been largely taken from previous work in this area at LLNL (Diaz and Braun 1984). They include kinetics for char combustion, kerogen pyrolysis and mineral decomposition as well as correlations for heat and mass transfer between particles and gas phases, and mass transfer coefficients describing transport of gas species inside the porous particles.

Simple Arrhenius' Law rate constant expressions are used for the chemical kinetics of char combustion, kerogen pyrolysis, and mineral decomposition. The overall char combustion kinetics make use of an unreacted-core model (Lenvenseiel, 1962) where limitations on the overall combustion rate are a result of gas to particle mass transfer, intraparticle diffusion and chemical kinetics. The intrinsic kinetics are assumed to be first order in oxygen and char. The kerogen is assumed to decompose to oil in a single step. During this overall decomposition reaction char and gases are also formed. The rate is assumed to be first order in kerogen. Decomposition of dolomite and calcite are assumed to be first order in the respective mineral.

Each particle size group is assumed to be characterized by a single temperature and convective heat transfer between gas and particles is computed based on standard correlations. An additional heat transfer mechanism, radiant transport, not included by Diaz is also included. The formulation is also simplified to reduce computational effort and results in a small enhancement of particle to gas heat transfer.

\subsection{Particle Grouping}

Since the modeling relies on discretization of any continuous particle size distribution into a finite number of particle groups each with a single particle size, the question arises as to how many particle groupings are required to do an adequate job. A 
categorical answer to this question is very difficult because of the variety of possible responses of a given particle to its environment and to the variety of possible particle size distributions. Consequently, this question was addressed using numerical experiments. In these experiments a lift-pipe module was used as the test bed because it was felt that it would be the most sensitive to variations in particle sizes.

The tests were aimed at using a realistic but simplified system. As a result it was assumed that entering the lift-pipe were particles having a uniform weight distribution in the size range from $0.2 \mathrm{~mm}$ to $7 \mathrm{~mm}$, along with a certain amount of very fine material. The non-fines portion of the solid was assumed to be made up of two types of material, spent oil shale (i.e. shale which has just been retorted and contains char) and burnt oil shale containing no char. The fines were assumed to be all spent material and constitute $1 / 3$ of the spent stream. The ratio of burnt to spent shale was taken as $3 / 1$. The geometry and proposed operation conditions of our laboratory lift-pipe were used in these numerical experiments. A series of runs were made in which the spent and burnt shale were divided into a varying number of equal weight fractions. An average particle size for each weight fraction was computed from the assumed flat distribution using a number weighted average. Slip velocities were estimated for each particle size from correlations of Pettyjohn and Christiansen (1948). Model calculations were then done to determine the temperature rise of the particles in the lift.

In order to compare the results the average temperature of all particles, except the fines, exiting the lift-pipe was used. The number of particles was continually increased until no change in computed average temperature was found, generally six groups. This result was then considered to represent the true continuous distribution result. Since computational time goes up markedly with the increase in particle groups it is desirable to use as small a number of groupings as possible. In examining the results of these numerical experiments it was determined that four groups did an adequate job. A number of different cases were run in which the effective combustion rate was altered by changing model parameters and it was found in each of the five cases studied the use of four particle groups would give an average particle temperature within 4 to $8 \%$ of that of the continuous distribution results, while the use of three groups lead to a 10 to $16 \%$ variation.

\subsection{Preliminary 4 Tonne-Per-Day Calculations}

Using the OSP model an overall process model for our 4 tonne-per-day pilot retort, shown schematically in Figure 1.1, has been generated. It consists of 33 OSP cornputational modules, about 150 solid streams and 21 gas streams. In this model the oil is assumed to be a component of the gas stream. In general 9 particle types are defined. These include four different size groups for first pass shale and four size groups for multi-pass shale along with a fines group. Actual breakdown and sizes are given later.

The primary units in the system and the modules used to model them are: 
- Lift Pipe - This unit is modeled using the LIFT PIPE module. Feeds to this unit include an air injection stream and 9 solid streams. The 9 solid streams represent 5 size groups for first-pass (spent shale), 4 size groups for multi-pass (burnt shale)

- Delayed Fall Combustor (DFC) - This unit is modeled using the CO CURRENT module. As in the Lift Pipe 5 size groups of first-pass shale and 4 size groups of multi-pass shale. The gas exiting the Lift Pipe enters the DFC along with an optional air stream.

- Fluid-Bed Classifier (FBC) - This unit is modeled using the FLUID BED module. Since it assumes that fines are carried out with the gas stream exhausting from the DFC only 4 size groups for first-pass shale along with the 4 size groups for multi-pass shale enter this unit. The fluidizing gas entering the unit is assumed to be nitrogen.

- Fluid-Bed Mixer (FBM) - This two stage fluid-bed unit is modeled using three modules. A FLUID BED module for each of the two stages and a CNTR CURRENT module for the mixer head space. In the fluid-beds 4 raw shale size groups are input along with 4 multi-pass shale size groups. The fines in the raw feed are assumed to go immediately into the headspace module. The fluidizing gas entering the mixer is assumed to be nitrogen and is split into equal streams and fed to each of the two sides of the mixer. The gas exiting the FLLIID BED modules is combined and then enters the CNTR CURRENT module representing the head space.

- Pyrolyzer - This moving packed bed is modeled with three fluid-bed modules in series. The FLUID BED module is used because the flow of solids and gases is not unidirectional since the gases are removed from side ports. In each of the modules 5 first-pass shale particle size groups are used, along with 4 multi-pass shale size groups. The $5^{\text {th }}$ first-pass group is the fines which are assumed removed from the FBM gas effluent stream and returned to the pyrolyzer.

In addition to these primary units a variety of other simpler modules were employed to generated the final process model. The most important of these were ATTRITION modules which were used to generate fines from larger material. Two types of attrition were employed. First, it was assumed that attriticn of the raw shale would occur in the FBM and Pyrolyzer. Since with the current models attrition can only be handled in an approximate fashion and the influence of particle size on Pyrolyzer operation is small, the raw attrition was assumed to occur after the Pyrolyzer. A simple attrition formulation was used in which $35 \%$ of each size fraction of first-pass shale was assumed to break into fines. A second form of attrition was assumed to occur after the particles had passed through the Lift Pipe. Here it was assumed that some of the ash layer (shale with kerogen or char) would break off the particles and form fines. This attrition was only applied to first pass particles. It was assumed that $50 \%$ of the ash layer on each particle group would attrite in this fashion.

As described above two types of particles are assumed to be present in the system. There are first pass particles which are fed in initially as raw shale and then become 
UCID 16986-90-1/2

spent shale in the FBM and Pyrolyzer. The second class of particles the multi-pass particle are those which have been around the loop more than once. The first-pass particles are merged into the multi-pass particles after the FBC. A MERGE STRMS module is used to combine the first and multi-pass particles size group by size group. All properties and compositions of the merged particles are obtained by flow weighted averages of the incoming particles.

For the model runs described below the source of solids in the system is assumed to be from a $24 \mathrm{gpt}$ oil shale. Shale density and kerogen content were estimated from correlations given by Diaz (1984) and result in a computed density of $2230 \mathrm{~kg} / \mathrm{m}^{3}$ and a kerogen weight fraction of 0.135 . For simplicity this computed density is maintained for all types of solids in the system. Besides the kerogen, the feed shale is assumed to be $29 \%$ dolomite and $8 \%$ calcite. The remainder of the shale, $49.5 \%$ is assumed inert. The other solid that can exist in the system is char which comes from the pyrolysis of kerogen. It is assumed that in the pyrolysis reaction $20.7 \%$ of the initial kerogen becomes char.

The particle size distribution was taken from screen analysis data of Mallon (1990). A sphericity of 0.6 was assumed for the particles based on the work of Carley (1980). In addition, using relations given by Carley it was computed that model particle size, defined as the diameter of a sphere with the same volume as the particle, could be obtained from screen analysis using the relation $\mathrm{d}_{p}=0.76 \mathrm{~d}_{s}$, where $\mathrm{d}_{s}$ is the nominal screen sizes. The particle groupings used for the raw shale are given in Table 2.1. The smallest cut measured was $-1 \mathrm{~mm}$. For modeling purposes this smallest fraction was arbitrarily broken into two fractions, $1-0.2 \mathrm{~mm}$ and fines. Half the material is assumed to be in each fraction and it was assumed that the average fines diameter was $0.05 \mathrm{~mm}$.

\section{Table 2.1 Base Case Raw Shale Particle Size Distribution}

\begin{tabular}{|c|c|c|c|}
\hline $\begin{array}{c}\mathrm{d}_{\mathrm{s}} \\
(\mathrm{mm})\end{array}$ & $\begin{array}{c}\mathrm{d}_{\mathrm{p}} \\
(\mathrm{mm})\end{array}$ & $\begin{array}{c}\text { Ave } \mathrm{d}_{\mathrm{p}} \\
(\mathrm{mm})\end{array}$ & $\begin{array}{c}\text { Weight } \\
(\%)\end{array}$ \\
\hline $7-4$ & $5.32-3.04$ & 3.9 & 24.3 \\
\hline $4-2.4$ & $3.04-1.82$ & 2.3 & 38.7 \\
\hline $2.4-1$ & $1.82-0.76$ & 1.1 & 23.2 \\
\hline $1-0.2$ & $0.76-0.152$ & 0.3 & 6.9 \\
\hline fines & & 0.05 & 6.9 \\
\hline
\end{tabular}

Kinetic and related parameters used were taken primarily from Diaz (1984), including the effective diffusivity to oxygen of the particles and the carbonate decomposition parameters. The pre-exponential coefficient and activation temperature for char combustion were obtained from Wallman (1990).

Particle velocities for the lift-pipe were computed using correlation described by Diaz (1984). The slip velocities for the $3.9 \mathrm{~mm}, 2.1 \mathrm{~mm}, 1.1 \mathrm{~mm}$ and $0.3 \mathrm{~mm}$ particles were computed to be $6.9 \mathrm{~m} / \mathrm{s}, 6.6 \mathrm{~m} / \mathrm{s}, 6.1 \mathrm{~m} / \mathrm{s}$ and $2.2 \mathrm{~m} / \mathrm{s}$ respectively. The fines were assumed to have a zero slip velocity. In the DFC the particle velocities were all taken to be $0.5 \mathrm{~m} / \mathrm{s}$ based on experimental measurements of Mallon (1990). The fines, however, vere assumed to travel at roughly the gas velocity of $2.8 \mathrm{~m} / \mathrm{s}$. 
The solid flow rates to the FBM were assumed to be $2.5 \mathrm{~kg} / \mathrm{min}$ of raw shale feed and $7.5 \mathrm{~kg} / \mathrm{min}$ of the recycled shale. The raw shale feed temperature was assumed to be $100 \mathrm{C}$. Gas injection into the system was assumed to include $0.5 \mathrm{~mol} / \mathrm{s}$ air at $500 \mathrm{C}$ into the Lift Pipe, $0.26 \mathrm{~mol} / \mathrm{s}$ of nitrogen at $600 \mathrm{C}$ into the FBC, $0.53 \mathrm{~mol} / \mathrm{s}$ of nitrogen at $500 \mathrm{C}$ into the FBM, and $0.015 \mathrm{~mol} / \mathrm{s}$ of nitrogen at $500 \mathrm{C}$ into the Pyrolyzer. The average pressure in the system was assumed to $100 \mathrm{kPa}$.

The base case model run required 24 loop iterations to reach a converged solution. It was assumed the solution had been reached when computed temperature changes from the previous loop were all less than $0.1 \%$. Guesses for internal stream compositions and properties were only approximate: with more sophisticated initial guesses the number of iterations can be reduced. The computation time for the run on an HP-9000/375 workstation was about 7 hours.

Selected results of the base case calculations are given in Tables 2.2-2.6. In these tables the solid particle type $M$ stands for multi-pass particles, type $S$ for first-pass particles and $F$ for fines. In Table 2.2 results for the Lift Pipe are given. Notice that the particles which get the hottest are the largest first or single pass particles and the fines are the coolest. This reflects the relative coupling of the particles to the gas phase temperature. It is the $0.3 \mathrm{~mm}$ particles which undergo the largest change in char content because they are small enough to have a relatively low resistance to oxygen diffusion yet large enough so that their temperature rises above the gas temperature allowing for relatively rapid combustion kinetics.

Table 2.2a Lift Pipe Solids

\begin{tabular}{|c|c|c|c|c|c|c|}
\hline \multirow{2}{*}{$\begin{array}{c}\text { Ave } d_{p} \\
(\mathrm{~mm})\end{array}$} & \multirow[t]{2}{*}{ Type } & \multirow{2}{*}{$\begin{array}{l}\text { Rate in } \\
(\mathrm{kg} / \mathrm{min})\end{array}$} & \multicolumn{2}{|c|}{ \% Char } & \multicolumn{2}{|c|}{ Temp C } \\
\hline & & & In & Out & In & Out \\
\hline 3.9 & $\bar{M}$ & 2.11 & $\overline{1.5}$ & 1.5 & 494 & $\overline{510}$ \\
\hline 2.2 & $M$ & 3.14 & 1.0 & 0.9 & 493 & 518 \\
\hline 1.0 & $\mathrm{M}$ & 1.71 & 0.2 & 0.2 & 493 & 533 \\
\hline 0.3 & $\mathrm{M}$ & 0.54 & 0.0 & 0.0 & 493 & 563 \\
\hline 3.9 & $\mathrm{~S}$ & 0.35 & 3.0 & 2.4 & 490 & 758 \\
\hline 2.3 & $\mathrm{~S}$ & 0.56 & 3.1 & 2.1 & 493 & 718 \\
\hline 1.1 & $S$ & 0.34 & 3.1 & 1.7 & 493 & 704 \\
\hline 0.3 & $S$ & 0.10 & 3.1 & 1.2 & 493 & 687 \\
\hline 0.05 & $\bar{F}$ & 0.88 & 3.1 & 2.3 & 493 & 586 \\
\hline
\end{tabular}


Table 2.2b Lift Pipe Gases

\begin{tabular}{|c|c|c|}
\hline & In & Out \\
\hline Flow mol/s & 0.5 & 0.505 \\
Temp C & 500 & 583 \\
$\% \mathrm{O}_{2}$ & 21.0 & 13.0 \\
\hline
\end{tabular}

Table 2.3 presents results for the Delayed Fall Combustor unit. By comparing the change in oxygen concentration in DFC to that in the Lift Pipe it is seen that slightly more combustion occurs in the Delayed Fall Combustor. In the DFC the fines become hot enough so that the combustion kinetics speeds up to the point where nearly all their char is consumed. In contrast little additional combustion occurs in the largest particle because of the relatively large mass transfer resistance of the particle matrix. Also notice that most of the multi-pass particles have gotten hot enough to allow some combustion of their char to occur. This along with the longer residence time in the DFC than the Lift Pipe results in less variation between single and multi-pass particle temperatures than in the Lift Pipe.

Table 2.3a Delayed Fall Classifier Solids

\begin{tabular}{|c|c||c||c|c||c|c|}
\hline $\begin{array}{c}\text { Ave } \mathrm{d}_{\mathrm{p}} \\
(\mathrm{mm})\end{array}$ & Type & \multicolumn{2}{c||}{$\begin{array}{c}\text { Rate in } \\
(\mathrm{kg} / \mathrm{min})\end{array}$} & \multicolumn{2}{|c|}{ \% Char } & \multicolumn{2}{|c|}{ Temp C } \\
\hline \hline 3.9 & $\mathrm{M}$ & 2.11 & Out & In & Out \\
\hline 2.2 & $\mathrm{M}$ & 3.13 & 1.5 & 1.4 & 510 & 582 \\
1.0 & $\mathrm{M}$ & 1.71 & 0.9 & 0.8 & 518 & 627 \\
0.3 & $\mathrm{M}$ & 0.56 & 0.1 & 533 & 651 \\
\hline 3.9 & $\mathrm{~S}$ & 0.34 & 2.4 & 2.0 & 563 & 649 \\
2.3 & $\mathrm{~S}$ & 0.51 & 2.3 & 1.8 & 758 & 738 \\
1.1 & $\mathrm{~S}$ & 0.28 & 2.0 & 1.0 & 704 & 607 \\
0.3 & $\mathrm{~S}$ & 0.07 & 1.7 & 0.0 & 687 & 649 \\
\hline 0.05 & $\mathrm{~F}$ & 1.01 & 0.2 & 0.1 & 602 & 649 \\
\hline
\end{tabular}

Table 2.3b Delayed Fall Combustor Gases

\begin{tabular}{|c|c|c|}
\hline & In & Out \\
\hline Flow mol/s & 0.505 & 0.515 \\
Temp C & 583 & 649 \\
$\% \mathrm{O}_{2}$ & 13.0 & 3.5 \\
\hline
\end{tabular}

From the DFC particles move to the Fluid-Bed Classifier. Results for his unit are given in Table 2.4. Since the fluidizing gas in this unit was assumed to be nitrogen, no additional combustion of char occurs in this unit. The primary chemical change is the 
decomposition of dolomite. The table indicates that about $1 \mathrm{wt} \%$ of dolomite decomposes in the unit. One of the purposes of this unit is to allow additiona' time for particle temperature equilibration and the calculations indicate that at the $F B C$ exit, there is only a $21 \mathrm{C}$ spread between the hottest and coldest particles.

Table 2.4a Fluid-Bed Classifier Solids

\begin{tabular}{|c|c|c|c|c|c|c|}
\hline \multirow{2}{*}{$\begin{array}{l}\text { Ave } d_{p} \\
(\mathrm{~mm})\end{array}$} & \multirow[t]{2}{*}{ Type } & \multirow{2}{*}{$\begin{array}{l}\text { Rate in } \\
(\mathrm{kg} / \mathrm{min})\end{array}$} & \multicolumn{2}{|c|}{$\% \mathrm{Dol}$} & \multicolumn{2}{|c|}{ Temp C } \\
\hline & & & In & Out & In & Out \\
\hline 3.9 & $\bar{M}$ & 2.10 & 17.5 & 16.8 & $\sqrt{582}$ & 621 \\
\hline 2.2 & M & 3.13 & 21.6 & 20.6 & 627 & 627 \\
\hline 1.0 & $\mathrm{M}$ & 1.70 & 23.0 & 21.9 & 651 & 628 \\
\hline 0.3 & M & 0.56 & 21.7 & 20.6 & 649 & 628 \\
\hline 3.9 & $\bar{s}$ & $\overline{0.33}$ & 25.0 & $\overline{23.1}$ & 738 & 642 \\
\hline 2.3 & S & 0.51 & 29.1 & 27.5 & 707 & 632 \\
\hline 1.1 & S & 0.27 & 31.4 & 29.9 & 667 & 628 \\
\hline 0.3 & 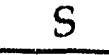 & 0.07 & 33.1 & 31.6 & 649 & 628 \\
\hline
\end{tabular}

Table 2.4b Fluid-Bed Classifier Gases

\begin{tabular}{|l|l|r|}
\hline & In & Out \\
\hline Flow mol/s & 0.29 & 0.269 \\
Temp C & 600 & 628 \\
\hline
\end{tabular}

In the Fluid-Bed Mixer raw shale feed is contacted by hot recycled solids. Table 2.5 gives computed results for this unit. The unit apparently does a fairly good job in transferring heat from the hot solids to the raw shale. On the average the temperature difference between raw and recycled shale is reduced from $527 \mathrm{C}$ for the inlet conditions to $27 \mathrm{C}$ at the outlet. This results in about $30 \%$ of the incoming kerogen pyrolyzing in the unit. The pyrolysis fraction is higher for the smaller particles because they heat up more rapidly. Little decomposition of the fines is computed because it is assumed they immediately are elutriated from the bed and are carried quickly out of the unit. These fines are assumed to be removed from the exit gas by a cyclone and and ultimately end up in the Pyrolyzer. 
Table 2.5a Delayed Fall Mixer Solids

\begin{tabular}{|c|c|c|c|c|c|c|}
\hline \multirow{2}{*}{$\begin{array}{l}\text { Ave } d_{p} \\
(\mathrm{~mm})\end{array}$} & \multirow[t]{2}{*}{ Type } & \multirow{2}{*}{$\begin{array}{c}\text { Rate in } \\
(\mathrm{kg} / \mathrm{min})\end{array}$} & \multicolumn{2}{|c|}{$\% \mathrm{Ker}$} & \multicolumn{2}{|c|}{ Temp C } \\
\hline & & & In & Out & In & Out \\
\hline 3.9 & $\overline{\mathrm{M}}$ & 2.11 & 0.0 & 0.0 & 624 & 516 \\
\hline 2.2 & $\mathrm{M}$ & 3.14 & 0.0 & 0.0 & 628 & 505 \\
\hline 1.0 & $\mathrm{M}$ & 1.71 & 0.0 & 0.0 & 628 & 501 \\
\hline 0.3 & M & 0.54 & 0.0 & 0.0 & 628 & 500 \\
\hline 3.9 & $\bar{S}$ & 0.61 & 13.5 & 12.7 & 100 & 450 \\
\hline 2.3 & S & 0.97 & 13.5 & 9.9 & 100 & 484 \\
\hline 1.1 & $S$ & 0.58 & 13.5 & 6.5 & 100 & 498 \\
\hline 0.3 & S & 0.17 & 13.5 & 4.5 & 100 & 500 \\
\hline 0.05 & $\overline{\mathrm{F}}$ & 0.17 & 13.5 & 13.5 & 100 & 429 \\
\hline
\end{tabular}

Table 2.5b Fluid-Bed Mixer Gases

\begin{tabular}{|c|c|c|}
\hline & In & Out \\
\hline Flow mol/s & 0.53 & 0.548 \\
T'emp C & 500 & 430 \\
Oil rate (kg/min) & & 0.07 \\
\hline
\end{tabular}

Table 2.6 gives computed results for the final unit, the Pyrolyzer. The results indicate that the solids equilibrate well in the unit. Nearly all of the kerogen pyrolyzes with the largest amount of unpyrolyzed kerogen remaining in the largest particles, reflecting their lower average temperature history.

Table 2.6a Pyrolyzer Solids

\begin{tabular}{|c|c|c|c|c|c|c|}
\hline \multirow{2}{*}{$\begin{array}{l}\text { Ave } d_{p} \\
(m m)\end{array}$} & \multirow[t]{2}{*}{ Type } & \multirow{2}{*}{$\begin{array}{l}\text { Rate in } \\
(\mathrm{kg} / \mathrm{min})\end{array}$} & \multicolumn{2}{|c|}{$\% \mathrm{Ker}$} & \multicolumn{2}{|c|}{ Temp C } \\
\hline & & & In & Out & In & Out \\
\hline 3.9 & $\bar{M}$ & 2.11 & 0.0 & 0.0 & 516 & 494 \\
\hline 2.2 & M & 3.13 & 0.0 & 0.0 & 505 & 493 \\
\hline 1.0 & M & 1.71 & 0.0 & 0.0 & 501 & 493 \\
\hline 0.3 & M & 0.54 & 0.0 & 0.0 & 500 & 493 \\
\hline 3.9 & $\overline{\mathrm{S}}$ & 0.60 & 12.7 & 0.5 & 450 & 490 \\
\hline 2.3 & S & 0.94 & 9.9 & 0.2 & 484 & 493 \\
\hline 1.1 & S & 0.55 & 6.5 & 0.1 & 498 & 493 \\
\hline 0.3 & S & 0.16 & 4.5 & 0.1 & 500 & 493 \\
\hline 0.05 & $\bar{F}$ & 0.17 & 13.5 & 0.2 & 429 & 493 \\
\hline
\end{tabular}


Table 2.6b Pyrolyzer Gases

\begin{tabular}{|c|c|c|}
\hline & In & Out \\
\hline Flow mol/s & 0.015 & 0.0554 \\
Temp C & 500 & 494 \\
Oil rate $(\mathrm{kg} / \mathrm{min})$ & & 0.16 \\
\hline
\end{tabular}

In addition to the base case calculations, three other runs were made to determine the robustness of the current model and the sensitivity of computed results to operating conditions and assumptions. In each case only a single parameter was varied. In the first variation, it was assumed that oxygen enriched air was to be injected into the Lift Pipe, raising the oxygen concentration to $30 \%$. The other two cases dealt with changes in the amount of fines present in the system. In one case, the high fines case, it was assumed that all the raw shale broke down into fines after passing through the FBM and the Pyrolyzer. In the last case it was assumed no fines were formed by attrition in the system and the only fines present were those in the raw shale stream which represented only $6.9 \%$ of the total feed.

Computed average solid temperatures for these three cases, plus the base case, are shown in Figure 2.1 In this figure average temperatures of first pass solids and the multi-pass solids at the exit of the major units are given. The figure indicates that the variation in operating parameters has the largest influence on the temperatures of the multi-pass solids exiting the combustion units, the Lift Pipe and the DFC. The finai temperatures attained by the solids as they exit the FBC varies by about $50 \mathrm{C}$. The hottest temperatures are attained in the system where all the raw shale attrites into fines. It is hotter because the char becomes more accessible to combustion and thus a larger fraction of the available char is consumed. 


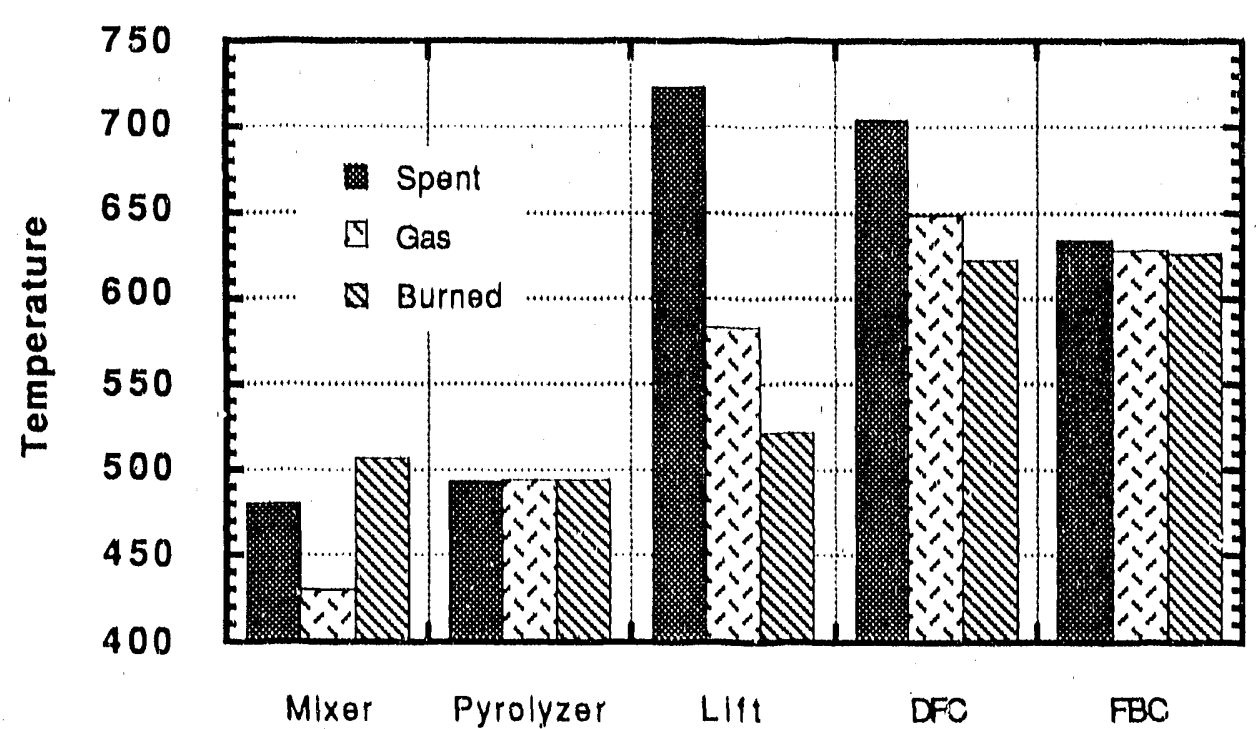

Figure 2.1 Computed Average Solid Temperatures at the exit of the Fluid-Bed mixer, Pyrolyzer, Lift, Delayed-Fall Combustor (DFC) and Fluid-Bed Combustor (FBC)

The oil generation in all four cases was near theoretical maximum. Since no oil coking was included in the model, oil generation is directly tied only to the degree of kerogen decomposition. In all four cases the temperature and residence time were sufficient to pyrolyze nearly all the kerogen. However, the split of oil production between FBM and Pyrolyzer showed a wider variation. In Table 2.7 the oil production as a percentage of the theoretical maximum is given for each of the runs. The total yield correlates with the temperature of recycled solids, with the hottest temperature having the highest yield. The relative amount of oil produced in the mixer is also highest for the highest recycle temperatures. This is simply a result of hotter temperatures reached by the input raw shale in the mixer leading to a greater degree of kerogen pyrolysis.

Table 2.7 Oil Production (theroetical $0.233 \mathrm{~kg} / \mathrm{min}$ )

\begin{tabular}{|c|c|c||c|}
\hline \multirow{2}{*}{ Run } & \multicolumn{3}{|c|}{ \% Theoretical } \\
\cline { 2 - 4 } & FBM & Pyrolyzer & Total \\
\hline Base & 30 & 68 & 98.5 \\
$30 \% \mathrm{O}_{2}$ & 37 & 61 & 98.9 \\
No Attrition & 22 & 73 & 95.6 \\
Ali Raw to Fines & 52 & 48 & 100 \\
\hline
\end{tabular}

The temperature reached by the system is a function of the amount of the produced char which is combusted. In Table 2.8 the temperature of solids leaving the Pyrolyzer and the fraction of carbon generated by kerogen decomposition which 
remains unburned are listed for the four runs. The run in which all raw shale was assumed to go to fines has the highest temperature and the lowest rejected (unburned) carbon. The coolest temperature is for the case when no attrition in the system is assur.ed to occur and in this case $30 \%$ of the generated carbon is unburned. Using the three runs with variable fines it appears that the Pyrolyzer temperature correlates well with the amount of attrition in the system (see Figure 2.1).

\section{Table 2.8 Rejected (unburned) Carbon as Percentage of Carbon Produced from Pyrolysis and Pyrolyzer Outlet Temperature}

\begin{tabular}{|c|c|c|}
\hline Run & $\begin{array}{c}\text { Rejected C } \\
\%\end{array}$ & $\begin{array}{c}\text { Temperature } \\
\text { C }\end{array}$ \\
\hline Base & 15 & 494 \\
$30 \% \mathrm{O}_{2}$ & 9 & 503 \\
No Attrition & 30 & 483 \\
All Raw to Fines & 0.3 & 522 \\
\hline
\end{tabular}

The computed decomposition of dolomite in the system ranged from 10\% to $32 \%$ of the incoming amount. Table 2.9 gives percentage decomposition for both fines and non-fines. Notice that even though the decomposition increases with temperature the amount of decomposition does not correlate directly with the temperature of the system. For example, the all fines case has the hottest temperatures leaving the Pyrolyzer yet it has less dolomite decomposition than the no attrition case, which has the coolest temperatures. The reason for this is the relative residence times of materials at temperature. In the all fines case all of the shale leaves the system as fines after the $D F C$. As a result much of the dolomite never sees the hot relatively long residence times of the FBC and FBM where most of the dolomite decomposition occurs. A 30C drop in temperature of recycled solid results from endothermic dolomite decomposition in the base case.

Table 2.9 Overall Dolomite Decomposition

\begin{tabular}{|c|c|c|c|}
\hline \multirow{2}{*}{ Run } & \multicolumn{3}{|c|}{$\%$ Dolomite Decomposed } \\
\cline { 2 - 4 } & Fines & Non-Fines & Total \\
\hline Base & 0 & 21 & 21 \\
$30 \% \mathrm{O}_{2}$ & 30 & 27 & 27 \\
No Attrition & 0 & 32 & 32 \\
All Raw to Fines & 7 & 3 & 10 \\
\hline
\end{tabular}

These initial runs have indicated the basic modeling scheme is relatively robust. The computations were performed with a full set of streams and a relatively large number of modules. These initial runs also indicate the importance of the attrition process in the operation of the retort. Future work on the model will concentrate on bringing each of the important modules to a state in which they incorporate a minimum acceptable set of physics and chemistry. Improvements needed to reach this state include incorporation of oil cracking, consideration of the influence of particle size 
on residence times in fluid-beds, integration of a scheme for computing velocities into the Lift Pipe module, and other physical and chemical processes.

\subsection{References}

2-1. Diaz, J.C., and Braun, R.L. 1984. Process Simulation Model for a Staged, FluidizedBed Oil-Shale Retort with Lift-Pipe Combuston Livermore, California: Lawrence Livermore National Laboratory, UCRL-53517.

2-2. Levenspiel, O., 1962. Chemical Reaction Engineering, p. 341-357, New York: John Wiley and Sons Inc.

2-3. Pettyjohn, E.S., and Christiansen, E.B., 1948. it Effect of Particle Shape on FreeSettling Rates of Isometric Particles, Chem. Eng. Prog. 44(2) p. 157-172.

2-4. Singleton, M.F., Koskinas, G.J., Burnham, A.K., and Raley, J.H., 1986. Assay of Products from Green River Oil Shale, Livermore, California: Lawrence Livermore National Laboratory, UCRL-53273, Rev.1.

2-5. Mallon, R.G., 1989. Pilot Plant Cold Flow Tests, from $6^{\text {th }}$ Briefing on Oil Shale Research, p. 417, Livermore, California: Lawrence Livermore National Laboraticry.

2-6. Carley, J.F., 1980. Dimensions, Exterior Surfaces, Volumes, Densities and Shape Factors for Particles of Crushed Colorado Oil Shale in Two Narrow Sieve Fractions Livermore, California: Lawrence Livermore National Laboratory, UCRL-84583.

2-7. Wallman, P., 1990. Private Communication.

2-8. Mallon, R.G., 1989. Pilot Plant Cold Flow Tests, from 6th Briefing on Oil Shale Research, p. 421, Livermore, California: Lawrence Livermore National Laboratory. 


\section{Shale Oil Coking Kinetics Over Oxidized Recycle Shale}

\subsection{Introduction}

Shale oil produced by primary pyrolysis is known to undergo secondary reactions on the surface of the burned shale used as heat carrier in hot-recycled-solid (HRS) processes [1]. The gross chemistry of these secondary reactions is a degradation of a portion of the oil to coke with a stoichiometric coefficient of about $2 / 3$, and to light hydrocarbon gas $\left(\mathrm{C}_{4-}\right)$ with a stoichiometric coefficient of about $1 / 3$. These heterogeneous reactions are referred to as "coking" to be distinguished from homogeneous "cracking" reactions that occur simultaneously but produce $\mathrm{C}_{4}$ - gas as the only practically important oil degradation product. The heterogeneous coking reactions show selectivity toward the high-boiling fraction of the oil, producing a product oil that is considerably lighter than the primary oil.

The objective of the present work has been to determine the kinetics of the coking reaction such that predictions of both oil yield loss and firial oil product boiling-point distribution can be made for the HRS process. This paper presents both experimental and modeling results that have been obtained to this end.

\subsection{Model}

The model introduced in [1] treated the shale oil as a single component, thus excluding any selectivity effects. This model has been extended to encompass three pseudo-oil components: a light fraction termed "distillate" with an effective boiling point of $200^{\circ} \mathrm{C}$, a middle fraction termed "gas oil" with an effective boiling point of $400^{\circ} \mathrm{C}$, and a "vacuum gas oil (VGO)" fraction with the boiling point $500^{\circ} \mathrm{C}$. Shale oil produced by an HRS process contains approximately $50 \%$ distillate, $25 \%$ gas oil and $25 \%$ vacuum gas oil [2]. The model has the following mathematical form

$$
\begin{aligned}
& v \frac{\partial C_{i}}{\partial x}=-k a\left(C_{i}-C_{i}^{*}\right)-k_{c r a c} C_{i} \\
& \frac{\partial C_{s i}}{\partial t}=k e\left(C_{i}-C_{i}^{*}\right)-k_{\text {coke }} C_{s i} C_{s \Sigma} \\
& C_{i}^{*}=m_{o} \exp \left(-b T_{B P i} / T\right) C_{S i}{ }^{3} \\
& \mathrm{k}=\frac{\mathrm{k}_{0}}{1+\alpha \operatorname{Coke}^{2}} \\
& \mathrm{k}_{\mathrm{crac}}=2.5310^{8} \exp \left(-19350^{\circ} \mathrm{K} / \mathrm{T}\right) \quad \mathrm{s}^{-1} \\
& \mathrm{k}_{\text {coke }}=3.0710^{14} \exp \left(-19270^{\circ} \mathrm{K} / \mathrm{T}\right) \quad \mathrm{m}^{2} /(\mathrm{mol} \mathrm{s}) \\
& \text { for Coke>0.0002 } \mathrm{mmol} / \mathrm{m}^{2} \text { (mono-layer for } 5 \mathrm{~m}^{2} / \mathrm{g} \text { shale) }
\end{aligned}
$$


where,

$$
\begin{aligned}
& C_{i}=\text { oil concentration of component } \mathrm{i} \text { in the gas phase }\left(\mathrm{mol} / \mathrm{m}^{3}\right. \text { gas) } \\
& \mathrm{i}=\text { Distillate, Gas Oil, Vacuum Gas Oil } \\
& \mathrm{C}_{\mathrm{i}}^{*}=\text { oil concentration of component } \mathrm{i} \text { in equilibrium with } \mathrm{C}_{\mathrm{Si}} \\
& \mathrm{C}_{\mathrm{Si}}=\text { oil concentration of component } \mathrm{i} \text { on solid surface }\left(\mathrm{mol} / \mathrm{m}^{2} \text { surface }\right) \\
& \mathrm{C}_{s} \Sigma=\Sigma \mathrm{Csi}_{\mathrm{si}} \\
& \text { Coke }=\text { coke concentration on solid surface }\left(\mathrm{mol} / \mathrm{m}^{2} \text { surface }\right) \\
& \mathrm{v} \quad=\text { interstitial fluid velocity } \\
& \mathrm{k} \quad=\text { mass transfer rate coefficient } \\
& \text { ko = initial mass transfer rate coefficient (no coke on solid) } \\
& \alpha \quad=\text { pore plugging coefficient } \\
& \text { a } \quad=\text { shale surface area/reactor volume } \\
& \varepsilon \quad=\text { void space } \\
& \mathrm{T}_{\mathrm{BPi}}=\text { effective boiling point of oil component } \mathrm{i}\left({ }^{\circ} \mathrm{K}\right) \\
& \mathrm{T}=\text { temperature }\left({ }^{\circ} \mathrm{K}\right) \\
& \mathrm{m}_{\mathrm{O}} \text { = initial slope of equilibrium curve } \\
& \beta . \quad=\text { equilibrium curve temperature coefficient } \\
& x \quad=\text { distance coordinate along shale bed axis } \\
& \text { it }=\text { time }
\end{aligned}
$$

$\mathrm{m}_{0}, \mathrm{k}_{0}, \alpha$ and $\beta$ are fitted parameters, other parameters are determined a priori.

The physics of the model defined by Eqs [1] is similar to the interchange between the carrier gas and the solid adsorbent column in gas chromatography: oil from the vapor phase (at concentration $\mathrm{C}$ ) is transferred to and from the solid phase according to a first order rate process driven by the excursion from equilibrium $\left(C-C^{*}\right)$. The equilibrium curve in Eq (1c) is therefore very important for the exchange of oil between the vapor phase and oil adsorbed on the surface of the solid.

The equilibrium curve, Eq (1c) is also the model element that accomplishes coking reaction selectivity. The physical basis for this is simply that heavy oil is thermodynamically enriched in the adsorbed oil due to its lower vapor pressure. The form of Eq. (1c) is suggested by vapor-pressure considerations, specifically the ClausiusClapeyron relationship:

where,

$$
\mathrm{p}_{\mathrm{i}}^{*}=\mathrm{p}_{\mathrm{o}} \exp \left(-\Delta \mathrm{H}_{\mathrm{i}} /(\mathrm{R} \mathrm{T})\right)
$$

$\mathrm{p}_{\mathrm{i}}^{*} \quad=$ equilibrium vapor pressure of oil component $\mathrm{i}$ at temperature $\mathrm{T}$

$\Delta \mathrm{H}_{\mathrm{i}}=$ heat of condensation of oil component $\mathrm{i}$

coupled with Trouton's approximate rule for $\Delta \mathrm{H}_{\mathrm{i}}$ :

$$
\Delta \mathrm{H}_{\mathrm{i}}=\mathrm{b}^{\prime} \mathrm{T}_{\mathrm{BPi}}
$$

where $\mathrm{T}_{\mathrm{BPi}}=$ boiling point of oil component $\mathrm{i}$ 
For pure condensation $\beta^{\prime}$ is generally taken to be $21 \mathrm{cal} / \mathrm{mol}{ }^{\circ} \mathrm{K}[3]$, but in this work $30 \mathrm{cal} / \mathrm{mol}{ }^{\circ} \mathrm{K}$ was found to provide a better fit of the data. It can also be argued that chemical interactions between the adsorbed oil and the solid surface results in a steeper dependence of the equilibrium oil vapor pressure on the oil boiling point. The combination of Eqs. (2a) and (2b) together with a purely empirical third order dependence on adsorbate concentration produces the equilibrium relationship of Eq (1c).

Figure 3.1 shows Eq (1c) for the three oil components at a temperature of $500^{\circ} \mathrm{C}$. The adsorbed heavy oil is seen to exert ve."y low equilibrium vapor pressures at low adsorbate concentrations in agreement witt the physical picture of a strongly adsorbed oil up to a mono-layer of adsorbate. The mono-layer is filled at approximately $3 \mathrm{mg} / \mathrm{g}$ shale (shale of surface area $5 \mathrm{~m}^{2} / \mathrm{g}$ ), and hence the equilibrium curve rises rapidly above $3 \mathrm{mg} / \mathrm{g}$ shale $\left(\mathrm{m}_{\mathrm{O}}\right.$ of $\mathrm{Eq}(1 \mathrm{c})$ was fitted such that the total oil adsorbate under typical conditions was about $3 \mathrm{mg} / \mathrm{g}$ shale). The temperature $\left(500^{\circ} \mathrm{C}\right.$ in Figure 3.1) influences the equilibrium curves in accordance with $\mathrm{Eq}(1 \mathrm{c})$ : all three equilibrium curves rise much faster with adsorbate concentration at higher temperature.

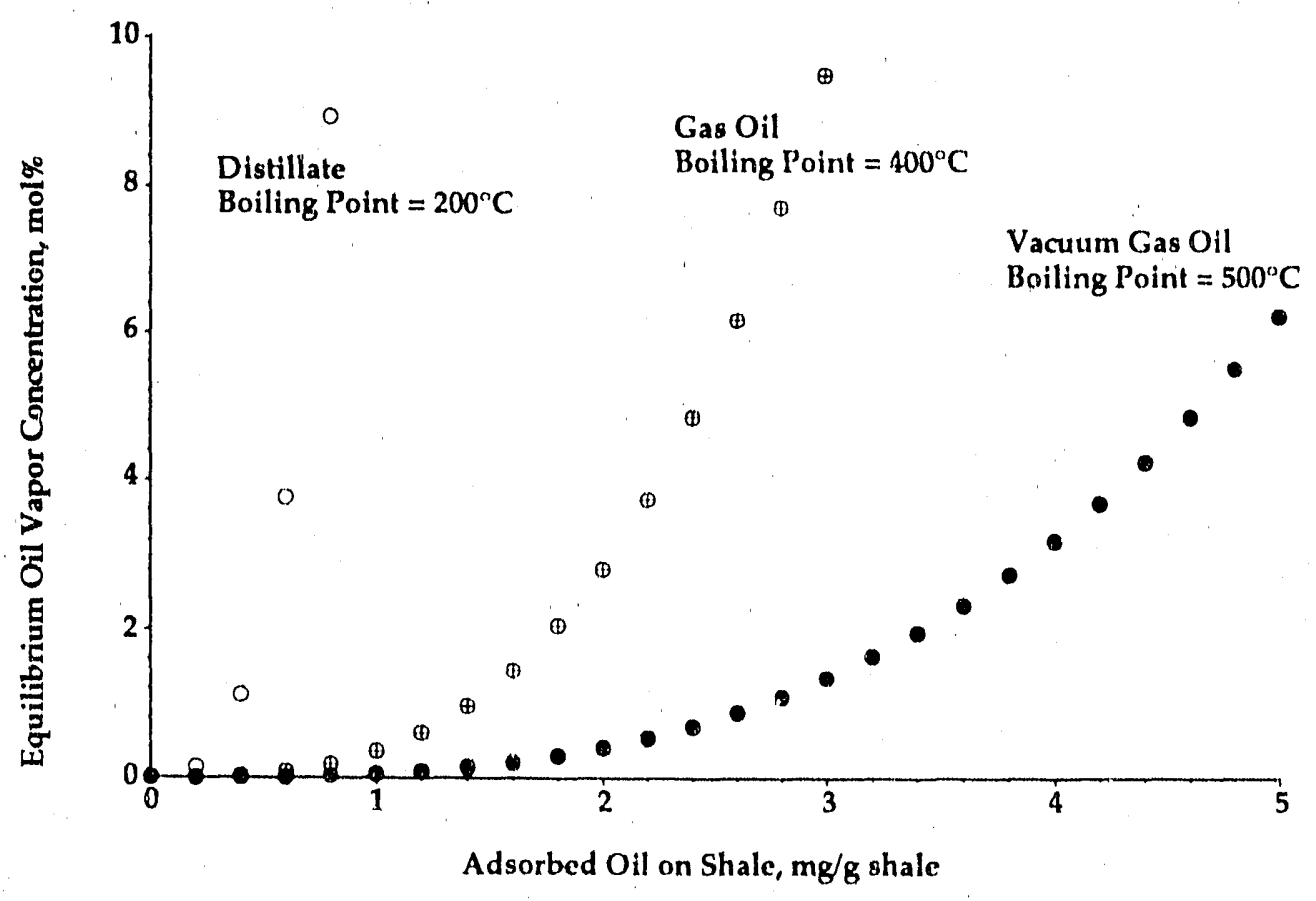

Figure 3.1 Model Liquid-Gas Phase Equilibrium for Oil Components at $500^{\circ} \mathrm{C}$

The kinetic part of the mass transfer, modeled in Eqs (1a) and (1b) together with parameters $k_{\mathrm{O}}$ and $\alpha$ of Eq (1d), is an approximation because all resistances, including intra-particle resistance, is lumped into one effective rate parameter $k$. Pore size distribution would affect $k$ but this relationship is unknown. For the purpose of simplicity, the whole pore surface area down to a pore size of $100 \mathrm{~A}$ is assumed to be reachable by diffusing oil, and therefore, this total surface area $\left(5 \mathrm{~m}^{2} / \mathrm{g}\right)$ is used in computing the model parameter a. Use of the total pore surface area introduces an error 
UCID 16986-90-1/2

if only a part of the surface is reachable by diffusing oil. However, any error will be compensated for by an appropriate matching of $a k_{o}$ value for the current experimental results. Finding an appropriate $k_{o}$ value for a shale with an entirely different pore structure would be difficult without experimental results for refitting the model.

The chemistry of the model of Eqs(1) is defined by Eqs (1e) and (1f) taken from [1]. These rates were determined in independent experiments performed with quartz as the solid surface. Further, the coking rate of Eq (1f) was determined for reaction on a surface already covered with coke. Hence, it is quite possible that the shale mineral surface catalyzes the coking reaction resulting in an initial coking rate significantly higher than that of Eq (1f). In the model calculations, the coking rate was assumed to be 10 times the value given by $\mathrm{Eq}$ (1f) until a mono-layer of coke (approximately $3 \mathrm{mg} / \mathrm{g}$ shale for shale with a surface area of $5 \mathrm{~m}^{2} / \mathrm{g}$ ) was formed. The main effect of this assumption was to convert more adsorbed oil to coke but the effect on the sum of adsorbed oil and coke was relatively minor.

The model parameters shown in Table 3.1 were used for all comparisons with the experiments.

Table 3.1. Model Parameters used for Comparisons with Experiments

\begin{tabular}{|l|l|l|}
\hline Parameter & Value & Unit $(\mathrm{mol}=\mathrm{MW} \mathrm{300)}$ \\
\hline $\mathrm{a}$ & $0.4310^{7}$ & $\mathrm{~m}^{2} / \mathrm{m}^{3}$ reactor \\
\hline$\varepsilon$ & 0.41 & $\mathrm{~m}^{3}$ void $/ \mathrm{m}^{3}$ reactor \\
\hline$V_{\text {inlet }}$ & $0.2-5.0$ (dep.on exprmt) & $\mathrm{m} / \mathrm{s}$ \\
\hline $\mathrm{k}_{\mathrm{O}}$ & $0.310^{-4}$ & $\mathrm{~m} / \mathrm{s}$ \\
\hline$\alpha$ & $0.110^{23}$ & $\left(\mathrm{~mol} / \mathrm{m}^{2} \text { surface }\right)^{-2}$ \\
\hline $\mathrm{m}_{\mathrm{O}}$ & $1.010^{23}$ & $\left(\mathrm{~mol} / \mathrm{m}^{2}\right)^{-3}\left(\mathrm{~mol} / \mathrm{m}^{3}\right)$ \\
\hline$\beta$ & 15.0 & () \\
\hline
\end{tabular}

\subsection{Experiments}

The short-exposure time apparatus [1] was used for establishing the model mass transfer parameters $k_{O}$ and $\alpha$. This apparatus consists of a fluidized bed for pyrolyzing a small shale sample followed by a packed bed of oxidized shale for coking the oil emerging from the fluidized bed. The apparatus is kinetic in nature; an oil vapor pulse enters the packed bed and emerges as an altered oil pulse from the the outlet. Particularly useful results were obtained by pyrolyzing a series of equal shale batches producing a series of equal inlet oil pulses to the packed bed. Results from such a series are shown in Figure 3.2. Here, the first and the second outlet pulse are compared with the inlet pulse (which was the same in the two experiments). Interestingly, the first oil pulse produces significantly more coke than the second pulse.' This is reflected by the areas under the outlet pulse curves that were used to compute the coke yields. 


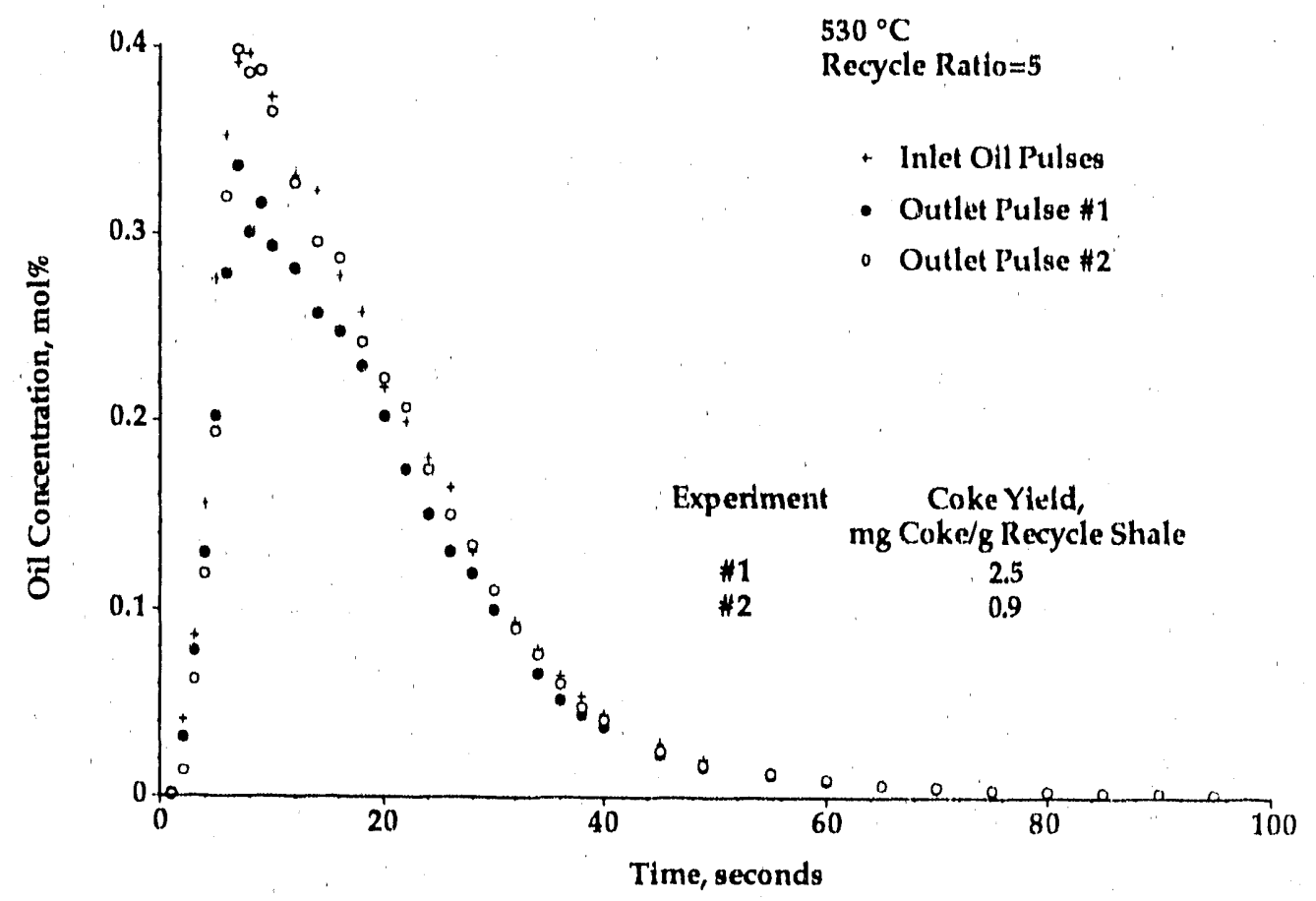

Figure 3.2 Multiple Oil Pulses through Fixed Bed of Oxidized Shale -- Experiment

Figure 3.3 shows the same experiment computed by the model. The model was driven by the same inlet oil pulses that were used in the experiments. The shape of the outlet pulse provided a measure of model matching ( the mass transfer coefficient $k_{0}$, for example, influenced strongly the dispersion of the pulse). With the parameters of Table 1 a good match between model and experiment was obtained; both the shapes and the areas of the model outlet pulses in Figure 3.3 match the experimentally determined ones in Figure 3.2. 


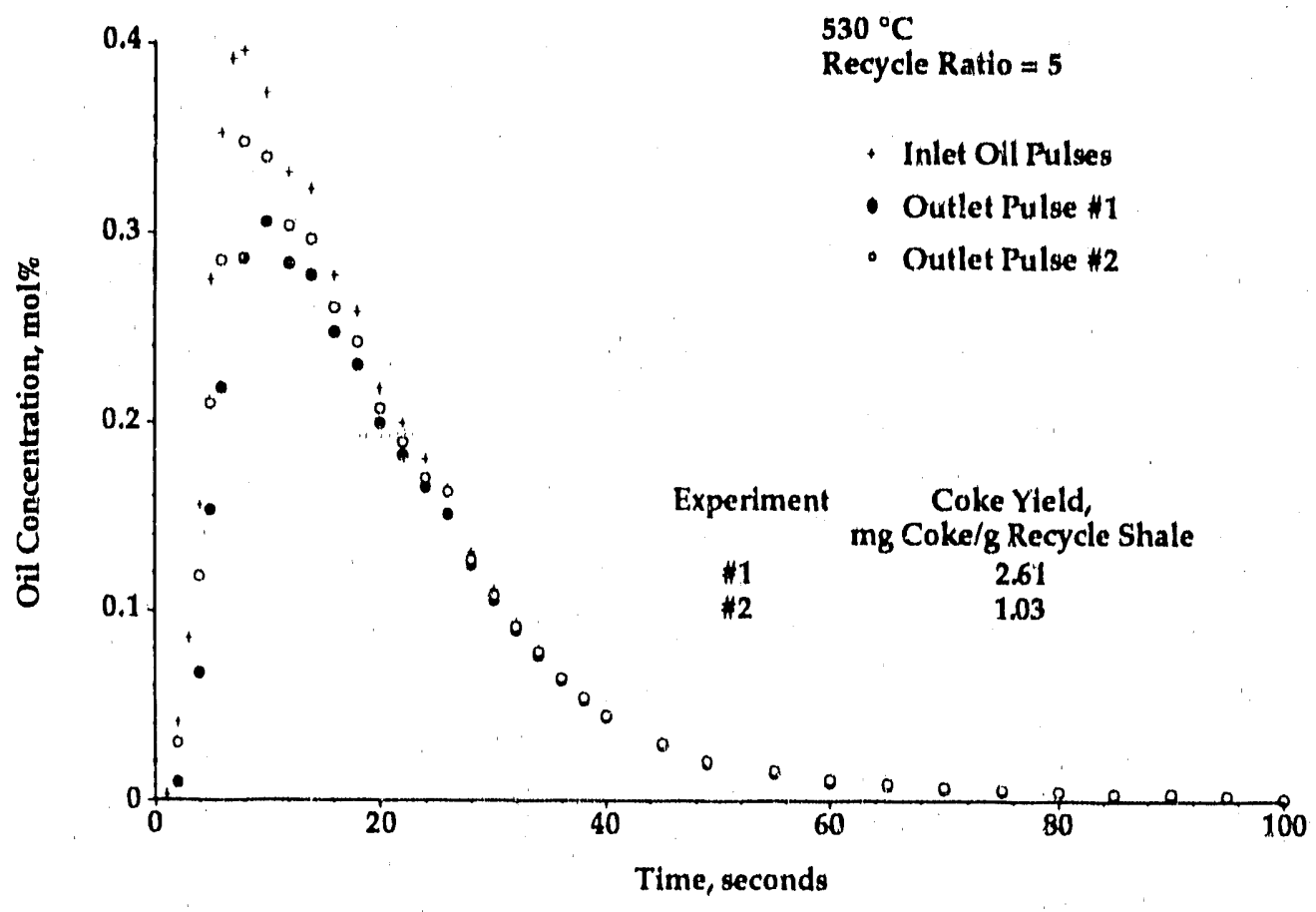

Figure 3.3 Multiple Oil Pulses through Fixed Bed of Oxidized Shale - Model

Figure 3.4 shows the coke yields for the full series of five consecutive pulses passing through the packed bed of oxidized shale. The figure shows how the first exposure of the oxidized shale to the oil pulse results in approximately a mono-layer of coke ( $2.5 \mathrm{mg}$ coke/g shale) while subsequent exposures only produce $0.8 \mathrm{mg}$ coke $/ \mathrm{g}$ shale. The model matches this trend very well because of the combined effect of a reduced mass transfer coefficient $k$ with coke yield, and a slow down of the model coking rate at the mono-layer level. 


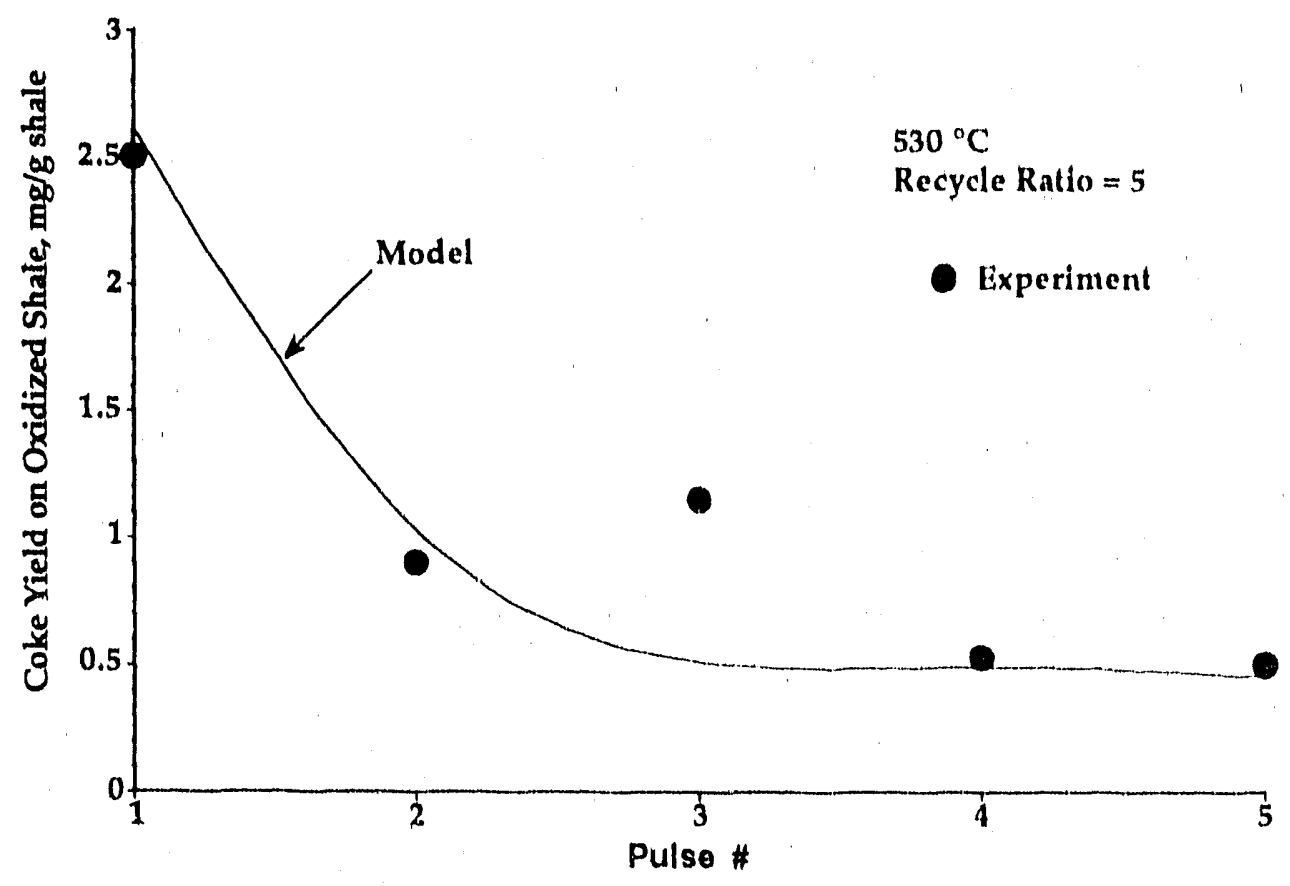

Figure 3.4 Multiple Oil Pulses through Fixed Bed of Oxidized Shale --. Comparison of Model Results with Experiments

Table 3.2. Coking Selectivity in Model Calculations for Oil Pulses

$\begin{array}{lccc} & \text { Distillate } & \text { Gas Oil } & \text { Vacuum Gas Oil } \\ \text { Starting Oil } & 50 \% & 25 \% & 25 \% \\ \text { Coked Oil } & 15 \% & 34 \% & 51 \%\end{array}$

Table 3.2 shows the model results with regard to oil quality. The coking selectivity toward the VGO fraction is quite strong, but it is not $100 \%$. The selectivity is the same for all pulses implying that the selectivity is not a function of severity, i.e. coking conversion. This is probably inaccurate because in reality the selectivity is expected to increase with decreasing severity, i.e. coke at a low conversion of the oll should mostly come from the VGO fraction. Unfortunately, the short-exposure time apparatus does not allow collection and characterization of the oil product.

Consequently, the oil quaiity results from the model cannot be compared with experiments.

Experiments have also been performed in the long-exposure time apparatus [1] for the purpose of testing the model. The apparatus consists of a packed-bed of oxidized shale and a unit where Fischer-Assay shale oil is vaporized into a hot carrier gas stream for feed to the packed bed. This apparatus allows collection and characterization of the product oil. However, the Fischer-Assay oil used in these experiments was significantly 
lighter than the primary oil in the short-exposure time experiments, containing no vacuum gas oil fraction. Model calculations were performed with an assumed feed oil of $50 \%$ distillate and $50 \%$ gas oil.

Figure 3.5 shows a yleld comparison between model calculations and experiments performed with varying shale exposure time, l.e. varying experimental run time in the long-exposure time apparatus. The difficulty in these experiments is to achieve typical HRS shale exposure times of only 1-2 minutes due to collection difficulties of minute quantities of product oil. However, the results from exposure times of 2-8 minutes show good agreement between model and experiment. Interestingly, the coking rate (the slope of the coke yield curve) continues to decline with multi-layers of coke on the solid surface. (All results here are above the coke mono-layer level). This is interpreted as pore mouth plugging and/or mass-transfer impediment by a countercurrent Stefan gas flux driven by outgassing coke. In the model this phenomenon is simply described by the parameter a in $\mathrm{Eq}(1 \mathrm{~d})$.

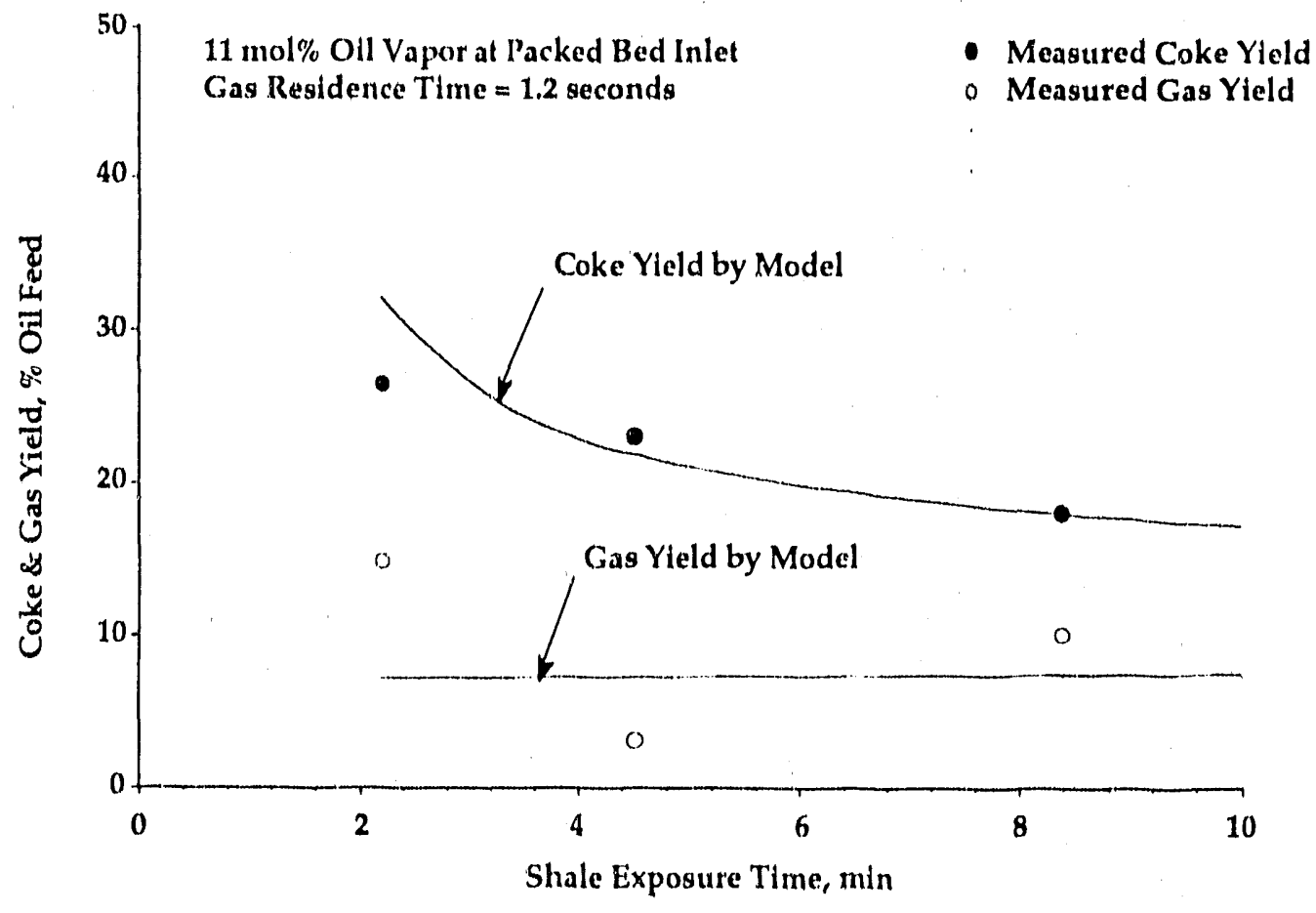

Figure 3.5 Coking of Oil Vapor in Packed Bed of Oxidized Comparison between Model and Experiment

A simulated distillation on the product oil obtained in the 4.5 minute experiment (Figure 3.5 , coke yield $=24 \%$ of the whole oil) shows that the selectivity of the coking process toward the heavy end of the oil is almost $100 \%$, i.e. the product oil boiling point distribution is approximately equal to the starting oil boiling point distribution minus $24 \%$ of the heaviest oil. In the model the selectivity is lower: the coked oil is $75 \%$ gas oil and $25 \%$ distillate in comparison with a starting oil of $50 \%$ gas oil, $50 \%$ distillate. The result, although imperfect, shows the right trend: coking affects mostly the heavier fraction of the oil. 
Figure 3.6 shows results from long-exposure time experiments together with model predictions for a temperature of $600^{\circ} \mathrm{C}$. (A brief contact between oil product vapors and hot recycle shale occurs in the HRS process before the recycle shale has transferred its heat to the raw shale). Again, the model matches the experiments quite well. It is interesting to note that the coke yield does not increase with the intrinsic coking kinetics of Eq (1f). Instead mass-transfer resistance is dominant at $600^{\circ} \mathrm{C}$.

However, the oil yield loss to light gas by the homogeneous cracking reaction increases quite substantially between $500^{\circ} \mathrm{C}$ and $600^{\circ} \mathrm{C}$. The cracking reaction is non-selective in the model, Eq (1a), leading to a lower selectivity for the combined cracking + coking reaction. For example, the 5-minute model results show that the coked + cracked oil is $60 \%$ gas oil and $40 \%$ distillate to be compared with the same starting oil of $50 \%$ gas oil, $50 \%$ distillate. Although these numbers may not be quantitatively correct, they show the correct qualitative trend: cracking that increases strongly with temperature is less selective toward undesirable heavy ends than coking is, and is therefore a less desirable reaction.

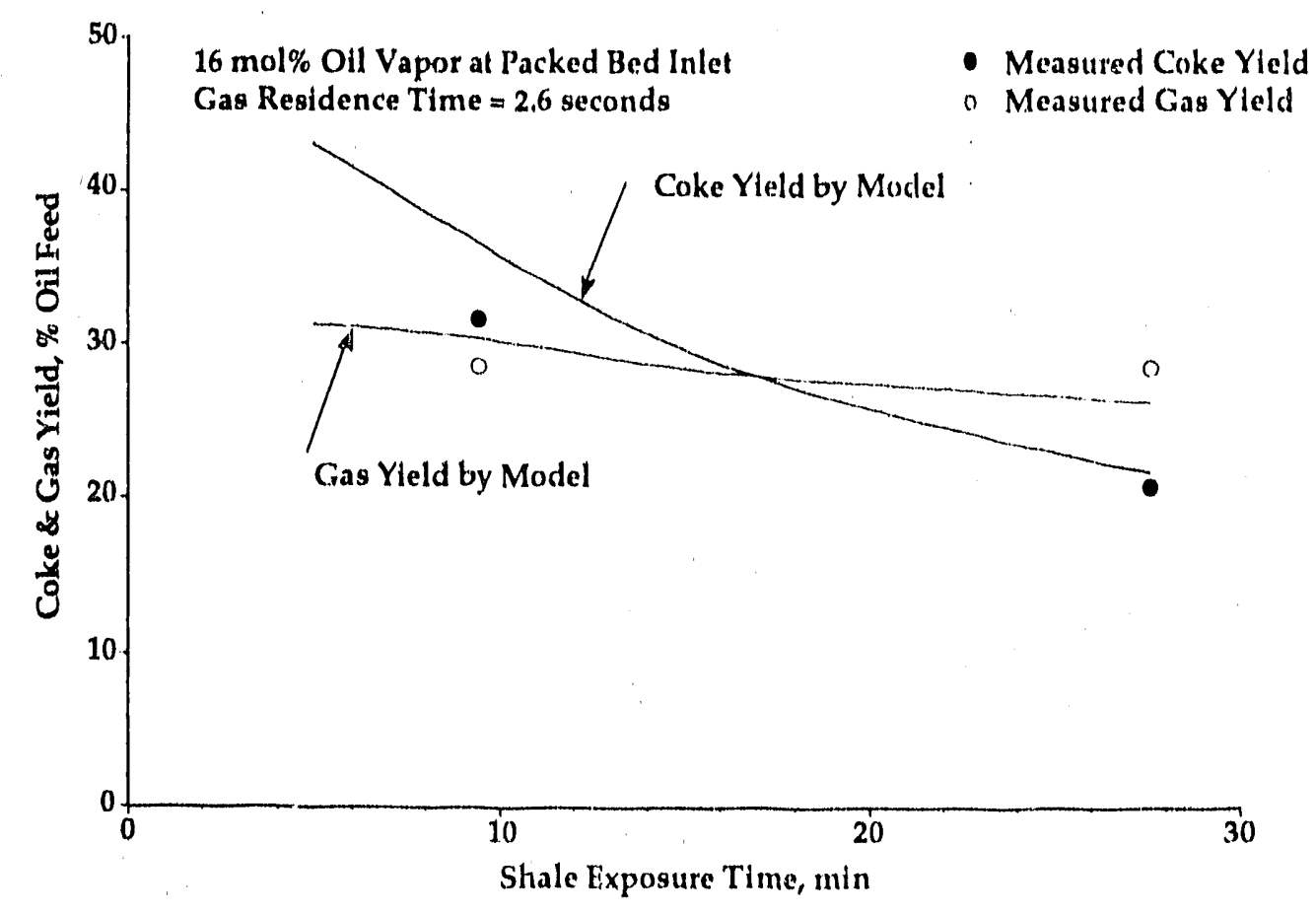

Figure 3.6 Coking of Oil Vapor in Packed Bed of Oxidized Shale at $600^{\circ} \mathrm{C}$ Comparison between Model and Experiment

\subsection{Conclusions}

The kinetics of shale oil vapor coking over typical recycle shale has been determined to a degree of accuracy adequate for prediction of oll yield losses in HRS processes with Green River oil shale. Comparisons between model and experimental results at widely different oil vapor concentraticns have shown good agreement. In the near future, the model will be applied to the LLNL HRS retort characterized by a fluidbed mixer followed by a packed bed pyrolyzer. Oil yield losses in this process are not 
expected to be too different from a simple fluidized-bed retort studied in [1]. The reason for this is that the coke yield corresponding to a mono-layer of coke (approximately $3 \mathrm{mg} / \mathrm{g}$ shale) is quite insensitive to processing conditions. However, conditions that substantially alter the surface area of the oxidized shale (such as carbonate decomposition) will affect this mono-layer of coke when expressed per $g$ of oxidized shale. For typical conditions (recycle surface area of $5 \mathrm{~m}^{2} / \mathrm{g}$ producing a mono-layer of $3 \mathrm{mg}$ coke/g shale), this coke mono-layer corresponds to an oil yield loss of the order $10 \%$.

Experimentally coking has been shown to remove selectively the heaviest oll components of the shale oll. This favorable result is explained by the model on purely physical grounds: the adsorption process for transferring oil from the vapor phase to the solid phase is interpreted as a partial condensation process that enriches heavy ends in the adsorbate. Non-selective chemical coking of this adsorbate produces the correct net result that coke is mostly derived from the heaviest fraction of the oll.

\subsection{References}

3-1. Wallman, P.H., Singleton, M.F., Taylor, R.W. "Cracking and Coking of Shale-Oil Vapors", 23 rd Annual Oil Shale Symposium, Golden, Colorado School of Mines, 1990.

3-2. Tamm, P.W., Bertelsen, C.A., Handel, G.M., Spars, B.G., Wallman, P.H. "The Chevron STB Oil Shale Retort", Energy Progress 2. (1982), p.37.

3-3. Castellan, G.W. Physical Chemistry. Addison-Wesley Publishing Company, Reading, 1964. 

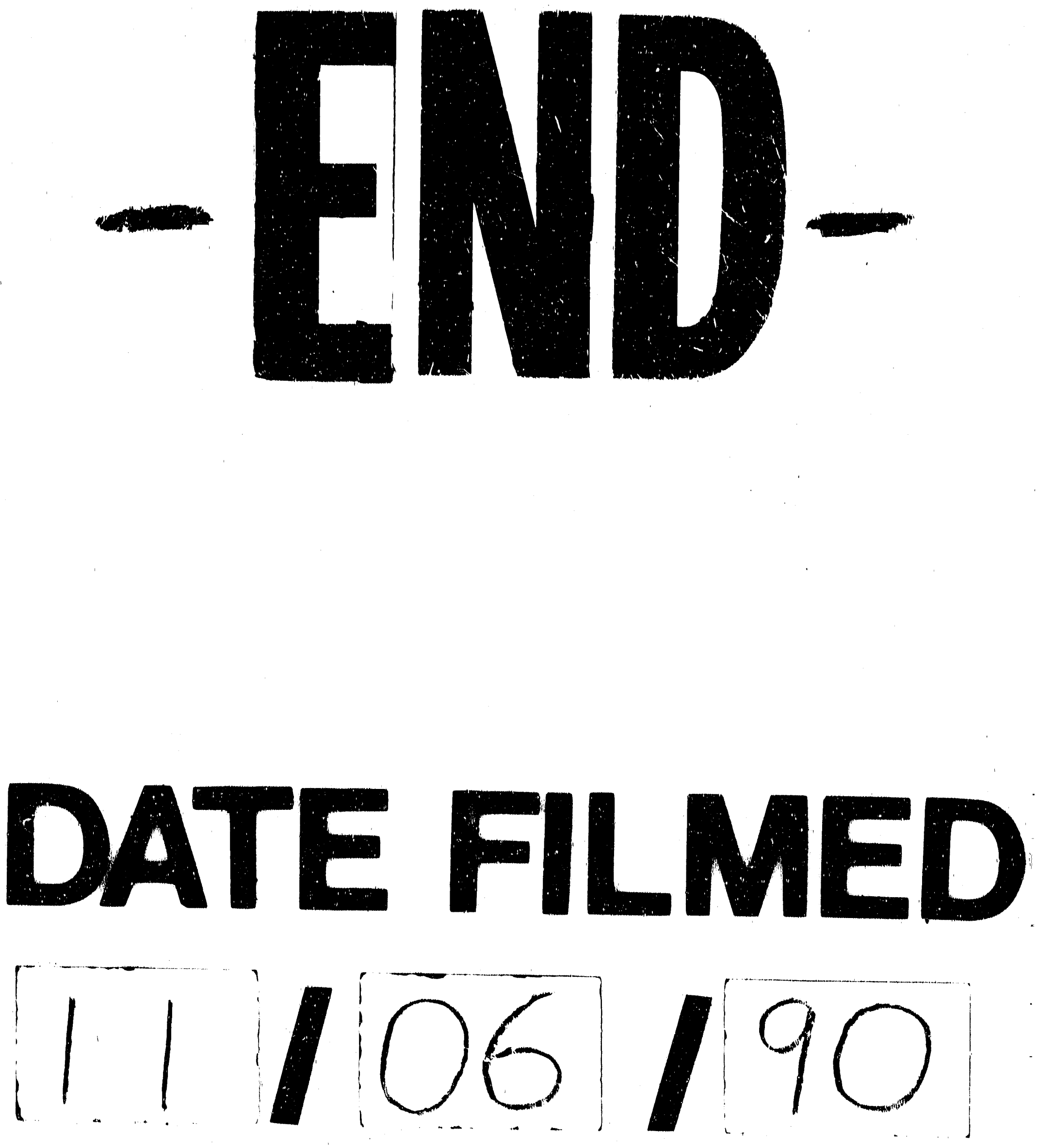
